\title{
ASPECTOS BIOLÓGICOS DE Anastrepha frateroulus (WIED., 1830) (DIPTERA, TEPHRITIDAE) EM DIETA ARTIFICIAL SOB DIFERENTES CONDIÇÕES DE LABORATÓRIO
}

\author{
JOSE CELSO MARTINS \\ Engenheiro Agrônomo
}

Orientador : Prof. Dr. JOSÉ ROBERTO POSTALI PARRA

Dissertação apresentada à Escola

Superior de Agricultura "Luiz de Queiroz", da Universidade de São Paulo, para obtenção do Título de Mestre em Ciências Biológicas. Área de Concentraçāo: Entomologia.

\footnotetext{
PIR ACICABA

Estado de São Paulo - Brasil

Dezembro - 1986
} 
A meus pais e irmã

OFERECO.

A Alba, Sërgio e Ricardo, pelo amor e incentivo

DEDICO. 


\section{AGRADECIMENTOS}

A Fundação Faculdade de Agronomia "Luiz Meneghel" (FFALM), pela oportunidade concedida para realização do Curso de Pós-Graduação.

Ao Dr. José Roberto Postali Parra, Professor Adjunto do Departamento de Entomologia da Escola Superior de Agricultura "Luiz de Queiroz" (ESALQ), pela orientação criterio sa e amizade.

Aos Professores do Departamento de Entomologia da ESALQ, pe los ensinamentos, especialmente ao Dr. José Djair Vendra min pelas sugestões, ajuda e incentivo; ao $\mathrm{Dr}$. Roberto Antonio zucchi pela identificação da espécie, razão deste trabalho e ao Dr. Sinval Silveira Neto pela elaboração da tabela de vida.

A FINEP, pelo financiamento desta pesquisa.

A CAPES, pela concessao da bolsa de estudo.

A Professora Maria Apparecida Valério Feltrin, pelos ensinamentos estatísticos, amizade e apoio.

Aos Professores do Departamento de Fitotecnia da FFALM que auxiliaram nas minhas obrigações, permitindo a conclusão desta pesquisa, em especial aos Professores Laila Herta Mihsfeldt, Leila Trevisan Brás e Robinson Osipe. 
Ao amigo Enrico de Beni Arrigoni; pela ajuda na coleta do material de campo.

Este autor, para nao pecar por omissão, agradece a todos aque les que direta ou indiretamente colaboraram na realização deste trabalho. 


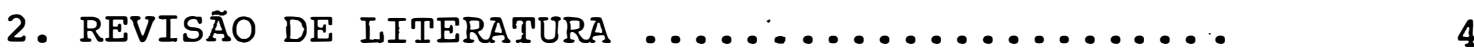

2.1. Hospedeiros de Anastrepha spp. 4

2.2. Efeito da temperatura, umidade relativa, fotoperíodo e outros parâmetros climáticos na ativiajade e desenvolvimento das

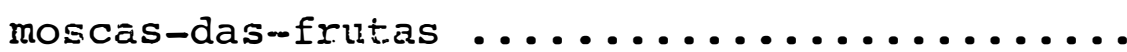

2.3. Técnicas de criação ...................... 12

2.3.1. Obtenধão de ovos ................ 12

2.3.2. Crìação em dietas artificiais 15

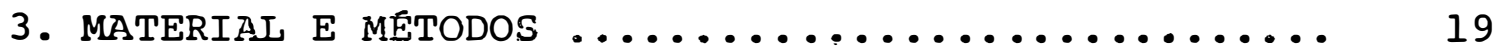

3.1. Obtenção do material de

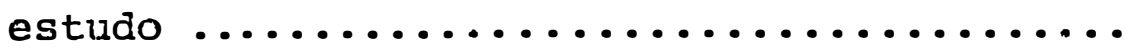

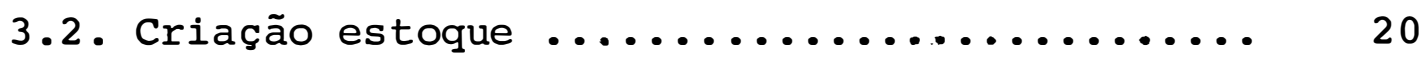

3.2.1. Local para postura .............. 20

3.2.2. Coleta dos ovos ................. 21

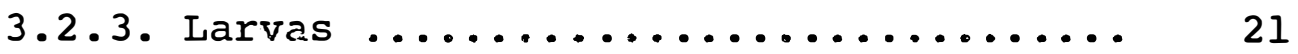


Página

3.2.4. Pupas $\ldots \ldots \ldots \ldots \ldots \ldots \ldots \ldots \ldots \ldots . \ldots \ldots$

3.2.5. Adultos ................... 23

3.3. Biologia em diferentes temperaturas ....... 23

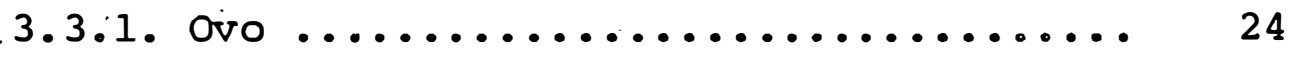

3.3.2. Larva ..................... 24

3.3.3. Pupa ...................... 24

3.3.4. Adulto ...................... 25

3.4. Tabela de vida de fertilidade ........... 26

3.5. Temperatura base (limiar de desenvolvimento) e constante térmica ............. 27

3.6. Comparação de dietas artificiais para criação de larvas ................... 27

3.6.1. Preparo das dietas ............. 27

3.7. Efeito de differentes condições de umida de na eclosão de larvas ............... 31

3.8. Influência da cor e tipo de receptáculo na postura ....................... 32

3.9. Influência do fotoperíodo no desenvolvi mento do inseto ..................... 33

3.10. Análise estatística ................ 34

4. RESULTADOS E DISCUSSÃO 36

4.1. Identificação da espécie ............ 36

4.2. Biologia de Anastrepha fraterculus (Wied., 1830) em diferentes dietas artificiais .... 36

4.2.1. Larva ................... 36

4.2.2. Pupa $\ldots \ldots \ldots \ldots \ldots \ldots \ldots \ldots \ldots \ldots . \ldots \ldots$ 
Página

4.3. Biologia de A. fraterculus em diferen-

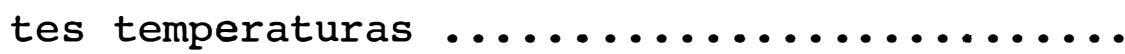

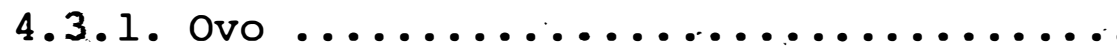

4.3.2. Larva ....................

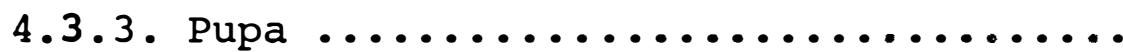

4.3.4. Adulto

4.3.5. Determinação das exigências tér micas de ovos de $A$. fraterculus .....

4.4. Comparação de substrato em diferentes cores para postura de $A$. fraterculus .......

4.5. Efeito de diferentes substratos no desenvolvimento embrionário de $A$. frater

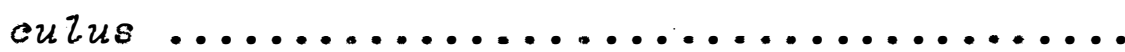

4.6. Efeito de diferentes teores de umidade da dieta na criação de $A$. fratereulus

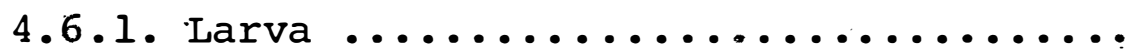

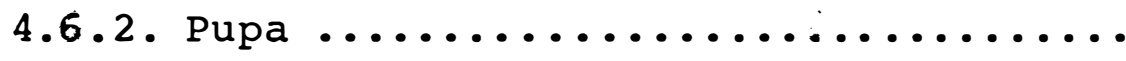

4.7. Efeito do fotoperíodo na duração dos períodos larval e pupal de $A$. fratércu

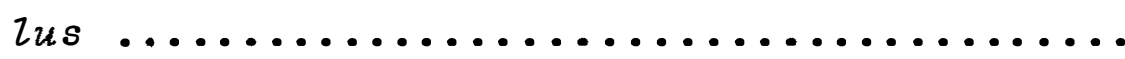

4.7.1. Larva ..................... 61

4.7.2. Pupa ..................... 62

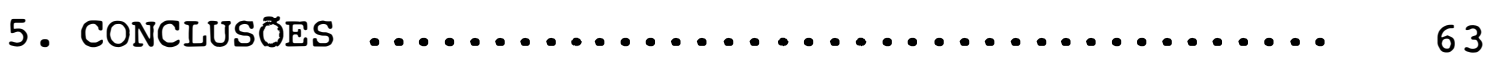

6. LITERATURA CITADA $\ldots \ldots \ldots \ldots \ldots \ldots \ldots \ldots \ldots \ldots \ldots \ldots$ 


\section{LISTA DE TABELAS}

Tabela

Página

1 Composição da dieta utilizada para criação de larvas de $A$. fraterculus

2 Composição da dieta utilizada para criação de adultos de $A$. fraterculus

criação de larvas de $A$ : fraterculus

Combinações de fotofase e escotofase para o estudo da influência do fotó período na duração e viabilidade das fases larval e pupal de $A$. fratercu Zus

5 Duração e viabilidade da fase larval de $A$. fraterculus em diferentes dietas artificiais. Temperatura:25 $\pm 0,5^{\circ} \mathrm{C}$; UR: $60 \pm 10 \%$ e fotofase: 14 horas ..........................

6 Duração e viabilidade da fase pupal de $A$. fraterculus em-diferentes die tas artificiais. Temperatura: $25 \pm$ $0,5^{\circ} \mathrm{C} ; \mathrm{UR}: 60 \pm 10 \%$ e fotofase: 14 horas ........................... 
7 Duração e viabilidade da fase de ovo de $A$. fraterculus em ' diferentes temperaturas; UR: $60+$ $.10 \%$ e fotofase: 14 horas ................

8 Duração e viabilidade da fase larval de $A$. fraterculus em temperaturas de 20 e $25^{\circ} \mathrm{C}$; UR: $60 \pm 10 \%$ e fotofase: 14 horas ...................

9 Longevidade médià de adultos de $A$. fraterculus. Temperatura: $25 \pm 0,5^{\circ} \mathrm{C}$; UR: $60+10 \%$ e fotofase: 14 horas

10 Períodos de pré-oviposição, oviposi ção, incubação, fecundidade de adul tos e viabilidade de ovos de $A$. fra terculus. Temperatura: $25 \pm 0,5^{\circ} \mathrm{C}$; UR: $60 \pm 10 \%$ e fotofase: 14 horas .........

11 Tabela de vida de fertilidade de $A$. fraterculus. Temperatura: $25 \pm 0,5$ ${ }^{\circ}$; $;$ UR: $60 \pm 10 \%$ e fotofase: 14 horás

12 Temperatura base (Tb) e constante tér mica $(K)$ da fase de ovo de A.fratercuZus. Temperaturas de 20,25 e $30{ }^{\circ} \mathrm{C}$. UR: $60+10 \%$ e fotofase: 14 horas ......... 
Tabela

Pãgina

13 Efeito de diferentes cores na postu ra de $A$. fraterculus. Temperatura: $25 \pm{ }^{\circ} \mathrm{C} ; \mathrm{UR}: 60 \pm 10 \%$ e fotofase:

14 horas ............................

14 Período de incubação e viabilidade de ovos de $A$.'fratercuzus, èm diferentes substratos. Temperatura: 25 $\pm 0,5^{\circ} \mathrm{C}$; UR: $60 \pm 10 \%$ e fotofase: 14 horas

15 Duração e viabilidade da fase larval de $A$. fraterculus em dieta arti ficial com diferentes teores de umi dade. Temperatura: $25+0,5^{\circ} \mathrm{C}$; UR: $60+10 \%$ e fotofase: 14 horas ............

16 Duração e viabilidade da fase pupal de $A$. fraterculus em dieta artifi cial com diferentes teores de umida de. Temperatura: $25 \pm 0,5^{\circ} \mathrm{C}$; UR: 60 $+10 \%$ e fotofase: 14 horas ................

17 Duração e viabilidade da fase larval de $A$. fraterculus em diferentes fotoperíodos. Temperatura: $25+$

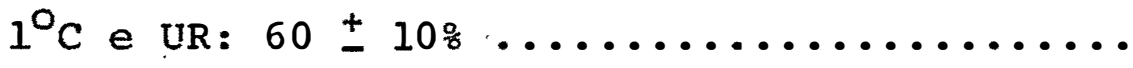


18 Duração e viabilidade da fase pupal de $A$. fraterculus em diferentes fotoperíodos. Temperatura: $25 \pm 1^{\circ} \mathrm{C}$ e $\mathrm{UR}: 60+10 \% \ldots \ldots \ldots \ldots \ldots \ldots \ldots \ldots \ldots \ldots \ldots$ 


\section{IISTA DE FIGURAS}

Figura

Página

1 Duração das fases larval e pupal de A. fraterculus em dietas artifi-

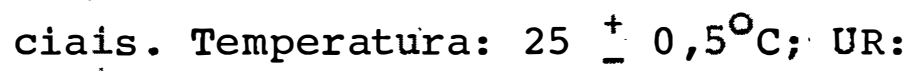
$60 \pm 10 \%$ e fotofase: 14 horas ............

2 Duração média de cađa fáse do ciclo biológico de $A$. fraterculus nas diferentes temperaturas: UR: $60 \pm 10 \%$ e fotofase $: 14$ horas ............

3 Curva de longevidade de machos de $A$. fraterculus baseada na distribuição de Weibull ........................

4 Número médio de ovos cọlocados por A. fraterculus: Temperatura: $25+$ $0,5^{\circ} \mathrm{C}$; UR: $60 \pm 10 \%$ e fotofase: 14

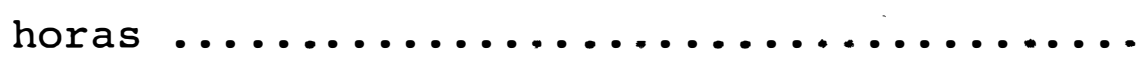

5. Viabilidade média de ovos de $A$. $f \underline{r}^{2} \underline{\underline{a}}$. terculus durante o período de ovipo sição. Temperatura: $25 \pm 0,5^{\circ} \mathrm{C}$; UR: $60 \pm 10 \%$ e fotofase: 14 horas ............ 
6 Duração das fases larval e pupal de A. fraterculus em dieta artificial com e sem adição de águạ. Temperatura: $25 \pm 1^{\circ} \mathrm{C}$; UR: $60 \pm 10 \%$ e foto

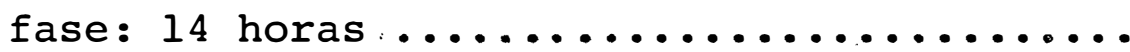

7 Viabilidade das fases larval e pupal de $A$. fraterculus em dieta arti ficial com e sem adição de água. Temperatura: $25 \pm 1^{\circ} \mathrm{C}$; UR: $60 \pm 10 \%$

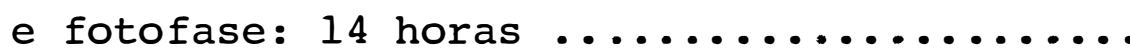




\section{ASPECTOS BIOLÓGICOS DE Anastrepha fraterculus (WIED,, 1830) (DÍPTERA, TEPHRITIDAE) EM DIETA ARTIFICIAL SOB DIFERENTES CONDICQÕES DE LABORATÓRIO}

Autor: José Celso Martins

Orientador: Dr. JOSE ROBERTO POSTAII PARRA

\section{RESUMO}

O objetivo da presente pesquisa foi desenvolver uma técnica de criação para Anastrepha fraterculus (Wied., 1830), utilizando-se dietas artificiais. Avaliou-se o efeito de diferentes dietas, temperaturas e fotoperíoảos na. bio logia do inseto, procurando desenvolver uma técnica de críação que fornecesse subsídios a novos métodos de controlẹ de praga e que facilitasse estudos ecológicos e etológicos des ta importante espécie de mosca-das-frutas..

Pode-se concluir que a dieta artificial à base de bagacilho de cana, germe de trigo e levedura é promissora para criação de $A$. fraterculus, muito embora tenha pro porcionado uma baixa viabilidade total. A temperatura de $25^{\circ} \mathrm{C}$ foi a mais adequada para criação desta espécie, sendo que nesta temperatura a longevidade dos machos foi significa 
tivamente maior do que a das fêmeas. A capacidade de postura e a viabilidade dos ovos decresceram com a idade das fêmeas, sendo que os valores da taxa líquida de reprodução e da razão finita de aumento atestaram a adequação nutricional - da dieta artificial à base de bagacilho de cana, germe de trigo e levedura. A temperatura base para a fase de ovo de A. fraterculus foi de $6,3^{\circ} \mathrm{C}$ com una constante têrmica de 61,26 GD. O substrato de cor vermelha, no 93 docódigo Universal de Cores de Seguy (1936), foi omais adequado como local de postura, sendo que para haver eclosão, os ovos devem estar em contato direto com a água. Apesar disto, o excesso de água na dieta prejudica o desenvolvimento de $A$. fraterculus. A.melhor combinação de fotofase:escotofase para criação des ta espécie foi 14:10. 


\title{
BIOLOGICAL ASPECTS OF Anastrepha fraterculus (WIED,, 1830) (DIPTERA, TEPHRITIDAE) ON ARTIFICIAL DIET UNDER DIFFERENT LABORATORY CONDITIONS
}

\author{
Author: José Celso Martins \\ Adviser: Dr. JOSE ROBERTO \\ POSTALI PARRA
}

\section{SUMMARY}

The objective of this study was to develop a technique for rearing Anastrepha fraterculus (Wied., 1830), using artificial diets. The effect of different temperature and photoperiods on this insect's biology was evaluated in an attempt to develop a rearing technique which provided subsidies for new methods of pest control and which facilitated ecological and ethological studies on this important fruit fly species.

It was concluded that an artificial diet consisting of sugarcane bagasse; wheat germ and yeast is promising for rearing $A$. fraterculus although it rendered a low total viability. The most adequate temperature for rearing. this species was $25^{\circ} \mathrm{C}$; at this temperature the longevity of males was significantly higher than that of 
females: Egg laying capacity and viability decreased with age of females, and the net reproduction rate values and the values of the finite ratio of increase attested to the nutritional adequateness of the artificial diet consisting of sugarcane bagasse, wheat germ and yeast. The threshold of temperature for the egg phase of $A$. fraterculus was $6.3^{\circ} \mathrm{C}$ with a thermal constant of $61.26^{\prime}$ degree days. The red color, no 93 on Seguy's color code (1936), was the most adequate egg laying substrate. The eggs should be in direct contact with water for hatching, however, excessive water in the diet jeopardizes the development of $A$. fraterculus. The best photophase:scotophase combination for rearing this species was $14: 10$. 


\section{INTRODUCAO}

As moscas-das-frutas (Diptera, Tephritidae) são insetos economicamente importantes por danificarem diferentes espécies de frutíferas, e, se não forem tomadas medidas de controle, os frutos tornam-se imprestáveis para o con sumo "in natura" e para a indústria.

No Brasil ocorre um grande numero de espécies de moscas-das-frutas pertencentes, principalmente, aos generos Ceratitis e Anastrepha. A espécie Ceratitis capitata (Wied.), conhecida como mosca-do-Mediterrāneo, foi referida pela primeira vez no Brasil em 1901 (IHERING, 1901) e hoje encontra-se disseminada em vários Estados do País. For outro la do, com relação ao gênero Anastrepha, dentre as inúmeras espẹcies referidas no Novo Mundo, Anastrepha fratercuzus(Wied.. 1830), a mosca sul-americana, é uma das mais freqüentes em nossas condições (ZUCCHI, 1978). 
Em nosso país, em condições de campo, a utili zaçao de iscas contendo diversos produtos químicos è umá prá tica rotineira, especialmente em pomares cítricos, para controle destas moscas (GALLO et alii, 1978). Quando o produto se destina à exportação, é feito um tratamento com fumigantes.' Nos últimos anos entretanto, os principais importadores de frutas brasileiras (Europa e EUA) estão apresentando restrições à utilização de produtos químicos com ação fumigante. Desta forma torna-se necessário o desenvol vimento de outras técnicas de controle no sentido de eliminar as larvas no interior dos frutos, como por exemplo, a utilização de irradiação.

Entretanto, para que este ou outros métodos possam ser utilizados, há necessidade de que sejam desenvolvidas técnicas de criação que permitam a proḍução de um gran de número de insetos em laboratório, para que as pesquisas possam ser continuamente realiżadas. Por outro lado, embora exista um grande volume de informações sobre $C$. capitata e outros gêneros de moscas-das-frutas, como Rhagoletis e Dacus, muito pouco se conhece sobre a bioecologia das especies de Anastrepha, especialmente em nossas condições, o que está dificultando a adoção đe novos métodos de controle para os frutos a serem exportados.

Assim, o objetivo da presente pesquisa foi de senvolver uma técnica de criação de $A$. fraterculus em dietas 
artificiais', procurando avaliar as suas exigências térmicas e de fotoperíodo em laboratório, com à finalidade de fornecer subsídios à criação massal do inseto, visando estudos ecológicos, etológicos e de controle da praga. 


\section{REVISÃO DE LITERATURA}

Tendo em vista 0 pequeno número de trabalhos realizados com Anastrepha fraterculus (wied., 1830), neste capítulo serão discutidos aspectos rel acionados com diversas, espécies de tefritídeos.

\subsection{HOSPEDEIROS DE Anastrepha Spp.}

A distribuição geográfica das moscas-das-frutas é muito ampla, ocorrendo praticamente em todo o mundo (BATEMAN, 1972) e segundo FOOTE (1967), só se conhecem as plantas hospedeiras de um quarto das espécies de tefritídeos neotropicais. Assim, SILVA et alii (1968) relataram a ocorrệncia de $A$. fraterculus em pelo menos 29 espécies de plantas, incluindo frutíferas, cafeeiros e tomateiros, sendo que WASBAUER (1972) referiu esta espécie em 55 hospedeiros diversos. 
Segundo MALAVASI et a $i$ i (1980), a lista de hospedeiros para Anastrepha spp. abrange 18 famílias de plan tas com 29 gêneros e 55 espécies. Por outro lado, GOMES (1973) considerou que, deste total, 34 são plantas nativas da América do Sul ou das Antilhas e 21 introduzidas da Europa, Africa e Ásia.

A intensidade de infestação de Ceratitis capi tata (Wied.) é maior nas espécies introduzidas, enquanto para Anastrepha spp., a maior'infestação tem sido registrada em espécies nativas (MALAVASI, 1977), havendo inclusive va-. riação em função do estágio de maturação dos frutos pois, FEHN (1977) constatou que a infestação de A. fraterculus e c. capitata foi. mais intensa nas cultivares de pêssegos de amadurecimento mediano, em relação àquelas semi tardias e tardias.

A ocorrência das moscas-das-frutas em pomares de mangas durante todo o ano é devido à presença de outros hospedei ros em frutificação constante, segundo HERRERA e VIÑAS (1977), podendo ocorrer em pomares comerciais ou em plantas isoladas (VAN DER MOLEN, 1982).

PARRÀ et alii. (1982) constataram que, em cafeeiro, o estágio de maturação dos frutos afẹta muito mais a dinâmica de $C$. capitata do que diversos parâmetros meteoroló gicos analisados.

Os tefritídeos podem utilizar plantas nao hos 
pedeiras que estejam próximas aos hospedeiros, para abrigo e alimentação (SMITH e PROKOPY, 1980; LANDOLT e HENDRICHS , 1983 e FRIAS et alii, 1984). Segundo MALAVASI (1984), parte da população de $A$. fraterculus permanece fora das árvores hospedeiras durante grande parte do dia e principalmente após escurecer, pois nestes locais passam a noite.

\subsection{EFEITO DA TEMPERATURA; UMIDADE RELATIVA; FOTOPERÍODO E OUTROS PARÂMETROS CLIMÁTICOS NA ATIVIDADE E DESEN- VOLVIMENTO DAS MOSCAS-DAS-FRUTAS}

A atividade de Anastrepha Zudens (Loew) é diminuída durante as horas mais quentes do dia, tendo sido observada uma mortalidade de $100 \%$ dos adultos expostos, por 3 horas, à temperatura de $40,5^{\circ} \mathrm{C}$. As pupas recém-formadas a presentaram mortalidade semelhante, com 7 horas de exposição, sendo as pupas "mais velhas" e larvas mais resistentes a estas altas temperaturas (DARBY e KAPP, 1933).

KECK (1951), estudando o efeito da temperatura sobre Dacus cucurbitae Coquillett, constatou que, entre 26,6 e $32,9^{\circ} \mathrm{C}$, 0 inseto atingiu a maturidade sexual mais rapidamente.

A dispersão de A. Zudenś é determinada, dentre outros fatores, por extremos de temperatura (BAKER et alii, 1944). A densidade populacional de A. fraterculus nao 
foi influenciada, segundo PUZZI e ORLANDO (1965), pela umidade relativa do ar, temperatura e precipitação pluvial.

Segundo ROSSILO e PORTILLO (1971), temperaturas médias de 14,3 a $17,4^{\circ} \mathrm{C}$ e umidades relativas entre 71 e 78\% são ideais para $A$. fraterculus. Observaram que na Argentina, nos meses mais frios do àno, A. fraterculus apresenta fecundação e oviposição reduzidas, causando menores danos às frutas cítricas.

PRESCOTT E BARANOWSKI (1971) determinaram as exigências térmicas de Anastrepha suspensa (Loew) e concluíram que para ovos, a constante térmica foi de 1129,6 graus-hora, para larvas 152,6 graus-dias e para pupas 251,2 graus-dias, baseando-se em temperaturas bases de 10, 9,7 e $14^{\circ} \mathrm{C}$ respectivamente. Segundo MESSENGER et alii (1958), os limites máximo e mínimo de temperatura para ovos de $C$. capitata são 35,6 e $11,7^{\circ} \mathrm{C}$ respectivamente.

HERRERAS E VIÑAS (1977) observaram que as maiores infestações das espécies A. fraterculus, Anastrepha distincta Greene e C. capitata ocorreram em períodos de altas temperaturas $\left(25-26^{\circ} \mathrm{C}\right)$ e baixas umidades relativas (70$75 \%)$. 
As espécies $C$. capitata, Dacus dorsalis Hen del $D$. cucurbitae e A. Zudens podem sobreviver em temperaturas abaixo de $14^{\circ} \mathrm{C}$, desde que o período com esta condição térmica não ultrapasse 60 dias. Temperaturas inferiores a $14^{\circ} \mathrm{C}$, por um período entre 60 e 90 dias, provocaram queda na reprodução e no desenvolvimento das moscas (MITCHELL et alii, 1977).

Segundo SHOUKRY e HAFEZ (1979), as temperaturas bases para o desenvolvimento de ovos, larvas e pupas de C. capitata foram $11 ; 5$ e $13^{\circ} \mathrm{C}$ respectivamente. Os mesmos autores afirmaram, ainda, que os adultos do referido inseto apresentaram um significante aumento de sua longevidade na temperatura de $25^{\circ} \mathrm{C}$ e UR de 60 a $65 \%$. PEDROSO (1972) obteve para C. capitata criada a $25,8^{\circ} \mathrm{C}$ em dieta artificial, duração de 11,30 dias para a fase pupal.

POLLONI (1981) concluiu que a duração do periodo pupal de Anastrepha obliqua (Macquart) foi mais longo no inverno do que no verão. O mesmo autor afirmou que o desenvolvimento de A. obliqua foi mais rápido do que o de Anastrepha bistrigata Bezzi, quando mantidas sob a mesma con dição térmica. 
Em temperaturas ao redor de $15^{\circ} \mathrm{C}$ (dados tomados macroclimaticamente), há predominância de $C$. capitata so bre Anastrepha spp. (PAVAN, 1978 e NASCIMENTO, 1980). Assim, segundo NASCIMENTO (1980), a baixa densidade populacional de 'C. capitata em relação à Anastrepha spp., em levantamen tos realizados na Bahia, deve ser determinada pela temperatu ra e competição exercida pelas espécies daquele gênero.

PARRA et alii (1982), trabalhando com C. cap $\underline{i}$ tata, concluíram que, dentre os parâmetros meteorológicos to mados macroclimaticamente, a temperatura foi, dentre os parâ metros analisados, o fator que mais afetou a dinâmica popula cional do inseto. Para os mesmos autores, o pico de ativida de diária de vôo ocorre entre 12 e 16 horas, quando a temperatura excede a $26^{\circ} \mathrm{C}$.

ARRIGONI (1984), em trabalho de levantamen̈to de populações de várias espécies de tefritídeos, em diferentes locais do Estado de são Paulo, concluiu que o comporta mento dos insetos deste grupo ë influenciado por parâmetros climáticos como temperatura e umidade relativa.

Segundo MALAVASI (1984), a temperatura ambien te influi na atividade diária de $A$. fraterculus e A. obliqua. Abaixo de $18^{\circ} \mathrm{C}$ e acima de $27^{\circ} \mathrm{C}$, as moscas permanecem em repouso, sendo que no intervalo. entre 22 e $26^{\circ} \mathrm{C}$, desempenham mais intensamente suas atividades. 
A dependência da temperatura na

biologia de várias espécies de tefritídeos foi referida por

BURK (1983) e FRIAS et alii (1984).

Com relação às pupas de $C$. capitata, ROSSILLO e PORTILLO (1971) relataram que não ocorre emergência de adultos em solos saturados, obtendo $100 \%$ de emergência em solos secos.

AZEVEDO e PARRA (no prelo) observaram, basean do-se em curvas de retenção para 2 tipos de solo (Podzoliza do Vermelho-Amarelo variação Lins e Latossolo Vermelho-Escu ro distrófico, textura argilosa), que pupas. de. C. capitata comportam-se diferentemente em cada um deles. Assim, no are noso (Podzolizado) houve um encurtamento do período pupal nas umidades menores, e no argiloso (Latossolo), a duração foi constante em todos os tratamentos. Por outro lado, a viabilidade da fase pupal foi drasticamente afetada no Latos solo, observando-se maiores valores nas condições mais secas; no Podzolizado, os maiores valores de porcentagem de emergêncìa ocorreram nas umidades intermediárias.

Segundo BATEMAN (1972), a baixa umidade do substrato reduz a sobrevivência de pupas, redundando em dimi nuição do peso dos adultos de $A$. Zudens.

Por outro. lado, SUPLICY Fo et aiii afirmaram nao existir correlação entre populações de moscas-das-frutas (C. capitata e Anastrepha spp.) com parâmetros 
meteorológicos como precipitação pluvial e temperatura.

O fotoperíodo pode afetar as principais ativi dades dos tefritídeos pois, segundo CHRISTENSON e FOOTE (1960), as moscas-das-frutas são inativas à noite e durante períodos de chuva. FLITTERS (1964) estudou o efeito do foto período, intensidade de luz e temperatura em $A$. ludens e con cluiu que, com a redução de intensidade luminosa no início e no final do período de 12 horas de luz, a temperatura entre 21,1 e $26,6^{\circ} \mathrm{C}$ e umidade relativa de 70 a $80 \%$, ocorreu uma diminuição do período de maturidade sexual em cerca de 16 dias.

TORNISIELO (1985) afirmou haver uma estreita dependência da luz para a oviposição de $C$. capitata, tendo registrado um maior número de ovos 3 a 4 horas após o início do período luminoso.

Trabalhando com azeitonas infestadas por Dacus oleae (Gmelin), LAUDEHO et alii (1978) concluíram que, ao amanhecer, as larvas prestes a se transformarem em pupas sao estimuladas a saíren dos frutos. ,o pico de saída dos frutos ocorre às 10 horas, diminuindo progressivamente até o anoite cer, não ocorrendo saída das larvas durante o período noturno.

Com fotoperiodo de 12:12 (fotofase:escotofase), verificou-se que o pico de saída das larvas de $C$. capitata para pupaçao ocorreu no início do período de luz. o rítmo 
circadiano permaneceu constante quando as larvas foram manti das. em período constante de escuro ou de luz (CAUSSE, 1974).

\subsection{TÉCNICAS DE CRIAÇ̃̃O}

\subsubsection{Obtenção de ovos}

Dado ao hábito de postura dos tefritídeos, uma das etapas mais difíceis e importantes é a da obtenção de ovos, justificando as inúmeras pesquisas que buscam um substrato adequado para postura. Assim, BAKER (1945) evidenciou que as fêmeas de $A$. fraterculus ovipositaram em metade de um fruto do qual havia sido retirada a sua polpa. Por outro la do, uma mistura de vaselina e parafina moldadas em meia esfera de tecido, serviram de substrato artificial para postura, de A. Zudens (Mc PHAIL e GUIZA, 1956).

Usando um recipiente plástico com formato de limão, contendo pequenos furos e com água em seu interior, TA NAKA (1965) obteve bons resultados para oviposição de C. capitata. Para D. dorsalis foi preciso adicionar suco de goia ba como atraente, sendo que para $D$. cucurbitae, o autor utilizou um pedaço de pepino colocado dentro dos recipientes plásticos, para obtenção de ovos.

Na Costa Rica, para postura de C. capitata, 
PELEG e RHODE (1967) usaram um tecido poroso em uma das faces da gaiola, permitindo que as fêmeas colocassem os ovos através deste tecido, os quais foram coletados em recipientes com agua, para evitar o ressecamento.

SIMON (1968), trabalhando com A. fraterculus, obteve postura em cúpulas confeccionadas em tecido encerado colocadas no alto das gaiolas. O autor testou ainda, como substrato de postura, garrafas e polietileno perfuradas e tecido de algodão, porém sem resultados satisfatórios.

O uso de frutos plásticos embebidos em suco de limão não foi eficiente como receptáculo de postura de A. suspensa. o problema só foi resolvido quando optou-se por recipientes em forma de conchas colocadas em pratos com água para evitar o ressecamento dos ovos (KAMASAKI et alii, 1970).

SIMÕES e PALUDETTI (1977) e SIMÕES et alii (1978) verificaram que uma meia esfera feita em musselina recoberta com parafina e vaselina foi um substrato excelente para postura de A. obliqua, Anastrepha sororcula (Zucchi) e A. bistrigata. Os autores verificaram que as duas primeiras espécies citadas têm preferência pelo receptáculo de cor ver 
de, enquanto $A$. bistrigata prefere a cor vermelha.

NAKAGAWA et alii (1978) compararam diferentes substratos para postura de $C$. capitata e concluiram que as cores preta e amarela foram as mais atrativas.

Usando um recipiente plástico com pequenas perfurações, coberto com folha de papel de seda molhado em suco de abóbora, SUGIMOTo (1978) conseguiu um aumento no número de ovos colocados por $D$. cucurbitae.

Em laboratório, esferas de cor amarela ofereceram uma maior atração para fêmeas de $A$. fraterculus do que outras cores (CYTRYNOWICZ et alii, 1982).

PEREZ (1983), adotando a técnica desenvolvida por PEDROSO (1972), obteve postura de C. capitata em tecido "voil" colocado em uma das faces da gaiola de criação, sendo os ovos mantidos em tiras de papel umedecido com agua desti lada.

Trabalhando com esferas de ágar coloridas. em vermelho, verde e amarelo, soUzA et alii (1984) observaram uma preferềncia de $C$. capitata para ovipositar nas de colora çao vermelha.

VARGAS (1984), comparando dois métodos para postura de $C$. capitata, concluiu que as fêmeas preferiam ovi positar nas garrafas plásticas perfuradas do que nas caixas com superfície telada. 
LOPES (1986) obteve posturas de A.fraterculus em laboratório usando dispositivos artificiais em meia esfera de consistência gelatinosa com ágar, água e anilina vermelha.

Os machos de tefritídeos, em geral, têm atração pela cor amarela, comportando-se da mesma forma tanto no campo como em laboratório (PROKOPY e BOLLER, 1971; PROKOPY, 1972 e BATEMAN, 1976). SALGADO (1975) constatou uma forte atração de C. capitata para as cores branca e amarela.

\subsubsection{Criação em dietas artificiais}

- No Brasil, PEDROSO (1972) foi o primeiro pesquisador a utilizar dieta artificial para criar tefritídeos, criando larvas de $C$. capitata numa dieta à base de cenoura desidratada, levedura de cerveja, ácido clorídrico e ácido benzôico.

SPISHAKOFF (1966) afirmou que o desenvolvimen to larval de:Anastrepha serpentina (Wiedemann) ocorreu em 11 dias, em dieta de cenoura e levedura desenvolvida por Rho de e Spishakof $(1965)$.

Maeda et alii (1953), citados por SALGADO (1979), foram os autores pioneiros da criaçãó massal de $C$. capitata. Nesta criação, as larvas foram alimentadas com uma dieta à base de óleo de germe de trigo e colesterol. Ob jetivando reduzir os custos, esta dieta foi modificada por 
FINNEX (1956) que substituiu o óleo de germe de trigo e colesterol por cenoura ralada e levedura dẹ cerveja.

Para criação massal de D. dorsalis, FINNEY (1956) utilizou uma dieta de cenouras cruas, obtendo uma via bilidade de ovos e larvas de $80 \%$ e de $95 \%$ para pupas.

SALGADO (1979) criou larvas de C. capitata na dieta modificada de Maeda et a $2 i i$ (1953) composta de agar, açucar, levedura de cerveja, caseína, mistura de sais (USP XII) ou sais de Wesson, colesterol, germe de trigo, Nipagin, cloreto de colina, água, ácido clorídrico, com um pH ajustado para 4,5 .

Para A. suspensa, KAMASAKI et alii (1970) usa ram uma dieta de cenoura liofilizada mais levedura hidroliza da para criação de larvas, enquanto que para adultos, util zaram açúcar granulado e cristais de suco de laranja mais proteína hidrolizada M, substrato também usado por RHODE (1957) para $A$. Zudens.

zUCOLOTO et alii (1979) testaram 24 dietas para larvas de Anastrepha spp. à base de levedura, germe de trigo, aveia, leite em po e soja, em diferentes concentrações, sendo comum a todas: ágar, farinha de trigo, sacarose e nipagin. Os melhores resultados foram obtidos nas dietas que continham: levedura $3,08 \mathrm{~g}$; sacarose $6,0 \mathrm{~g}$; farinha de trigo 4,0 g; ágar $1,0 \mathrm{~g}$; nipagin 0,5 $\mathrm{ml}$ e água destilada 150 ml e a outra em que se colocavam $4,5 \mathrm{~g}$ de levedura e $4,5 \mathrm{~g}$ de 
sacarose.

SIMON (1968) obteve resultados satisfatórios

criando larvas de $A$. fraterculus em dieta constituída de bagacilho de cana, germe de trigo, levedura e açúcar cristal.

PEREZ (1983) trabalhando com C. capitata, usou uma dieta à base de bagacilho de cana, levedura e germe de trigo para alimentação das larvas.

Os estudos de dieta para adultos de $A$. frater culus mostraram que carboidratos e água são suficientes para a sua sobrevivência, mas para que haja um desenvolvimento nor mal do embrião e necessária a adição de uma fonte protéica (BAKER; 1945).

Em testes de dietas para $D$. dorsalis, D. cucurbitae e C. capitata no Havaí, Hagen (1953) e Hagen e Finney (1950), citados por STEINER e MITCHELL (1966) constata ram que proteínas hidrolizadas comerciais podem oferecer. a maioria dos nutrientes exigidos por aquelas espécies, reduzindo o período de pré-oviposição e aumentando a fecundidade. PELEG e RHODE (1967) utilizaram como alimento para adultos de $C$. capitata, uma mistura de sacarose e levedura tipo $M$, com ótimos resultados.

Dietas sólida e líquida à base de levedura hidrolizada e açúcar foram testadas em $D$. oleae por TZANAKAKIS et alii (1967), resultando em maior preferência pela die 
ta líquida por parte das fêmeas, levando-as a uma maior oviposição.

SIMON (1968) obteve bons resultados na criagão de A. fraterculus usando, para adultos, uma mistura de proteína hidrolizada M, água e açúcar.

Estudos nutricionais foram conduzidos por DELANQUE (1955) que utilizou como dieta para adultos de $C$. capitata, banana sem casca, levedura, mel e água, borrifada na tela da gaiola de criação.

Uma mistura de açucar e proteína hidrolizada foi tida como o melhor alimento para adultos de $D$. cucurbi tae (SUGIMOTO, 1978). 


\section{MATERIAL E METODOS}

A pesquisa foi desenvolvida nos laboratórios de Biologia do Departamento de Entomologia da Escola Superior de Agricultura "Luiz de Queiroz", da Universidade de São Paulo, Piracicaba, com a espécie Anastrepha fraterculus (Wied., 1830) (Diptera, Tephritidae) .

\subsection{OBTENÇÃO DO MATERIAL DE ESTUdO}

Para o início da criação foram coletados pessegos da variedade Okinawa, provenientes da Fazenda Quinta do Pinhal, no município de Cabreúva, SP. Estes pessegos, que continham larvas de moscas-das-frutas em seu interior, foram colocados em caixas plásticas de coloração brancamedin do $30 \times 50 \times 15 \mathrm{~cm}$ contendo uma camada de areia fina na sua par te inferior (para facilitar a pupação) e mantidas em um tela do coberto de vidro localizado na área experimental do Depar 
tamento de Entomologia da ESALQ. As pupas das moscas-das-frutas foram coletadas através de peneịação diária, sendo trans feridas para placas de Petri $(1,3 \times 10 \mathrm{~cm})$, contendo no fundo uma camada de areia fina umedecida e recobertas por copos plásticos com a parte inferior telada. Estas pupas foram mantidas à temperatura de $25 \pm 2^{\circ} \mathrm{C}$; umidade relativa de $60 \pm 10 \%$ e fotofase de 14 horas até a emergência dos adultos, quando se procedia a transferência para gaiolas de cria ção, medindo $20 \times 15 \times 1.5 \mathrm{~cm}$, com capacidade para até 150 casais, ou gaiolas de $15 \times 15 \times 15 \mathrm{~cm}$ onde era colocado cada casal. Estas gaiolas eram de arame grosso (4 mm de diâmetro), e revestidas com tela branca de nailon, cujas malhas eram suficientemente finas para evitar a fuga das moscas. Em uma das laterais, ao invés de tela, colocou-se uma manga de tecido (morim), por onde era possível a manipulação das moscas -das-frutas.

Alguns exemplares adultos foram mortos e mantidos em álcool $70 \%$ para posterior identificação pelo Prof. Roberto Antonio Zucchi, do Departamento de Entomologia da ESALQ.

\subsection{CRIAç̃o estoque}

3.2.1. Local para postura

Como local de postura foi confeccionado um dis- 
co de espuma de plástico (utilizada para lavar louças) da marca "Esponjex", de coloração vermelha, n̊ 93, código universal de cores, SEGUY (1936), medindo $6 \mathrm{~cm}$ de diâmetro por $2 \mathrm{~cm}$ de altura. O disco era acondicionado em recipiente plás tico dè $6,3 \mathrm{~cm}$ de diâmetro por $2 \mathrm{~cm}$ de altura, contendo água para o umedecimento da espuma e recoberto por uma película de "Parafilm". O conjunto era colocado no interior da gaiola dos adultos, descrita em 3.1 .

\subsubsection{Coleta dos ovos}

Diariamente e sempre observando o mesmo horário (período vespertino), os ovos eram coletados do local de . postura, descrito no item 3.2.1., com auxílio de um pincel de pêlo de camelo número 0 . Inicialmente, retirava-se a película de "Parafilm" recolhendo-se os ovos que aí ficayam retidos. Posteriormente, eram coletados aqueles que permane ciam no fundo da caixa plástica e, finalmente, comprimia-se, entre os dedos, a espuma, para obtenção dos ovos que se encontravam no seu interior. Os ovos eram transferidos para placas de Petri $(1,3 \times 10 \mathrm{~cm})$ contendo água de torneira, e lá permaneciam até a eclosão das larvas.

\subsubsection{Larvas}

Com auxílio do pincel de pelo de camelo nume- 
ro 0 , as larvas recém-nascidas eram transportadas, uma a uma, para placas de Petri contendo a dieta padrão cuja composição era semelhante àquela utilizada no "Insect Attractants, Behaviour, and Bàsic Biology Research Laboratory, ARS, USDA, Gainesville Flórida, USA" (Tabela l).

TABELA 1 - Composição da dieta utilizada para criação de larvar de $A$. fratercuzus.

Metil parahidroxibenzoato $2,0 \mathrm{~g}$

Benzoato de sódio $2,0 \mathrm{~g}$

HCl concentrado

$8,1 \mathrm{ml}$

Formaldeído (20\%)

$0,6 \mathrm{ml}$

Sacarose $45 ., 0 \mathrm{~g}$

Germe de trigo.

$67,2 \mathrm{~g}$

Levedura

$67,2 \mathrm{~g}$

Bagacilho de cana (esterilizado) $135,0 \mathrm{~g}$

Agua $600,0 \mathrm{ml}$

Em cada placa de Petri, eram colocados $100 \mathrm{~g}$ de dieta padrão, suficientes para manter 25 larvas até a pupaçao. A transferência das larvas era feita com auxílio de um pincel número 0 sob um microscópio estereoscópico e apos a colocação das larvas na dieta, adicionavam-se $15 \mathrm{ml}$ de água em cada uma das placas de Petri. Esta dieta, adiciona da de água, foi comparada, com uma dieta que não recebeu esta suplementação, porém apresentando a mesma composição, sen do avaliadas a duração e a viabilidade larval nestes dois meios. 


\subsubsection{Pupas}

A medida que as larvas iam se transformando nas placas de Petri com dieta artificial, procedia-se a sua trans ferência, individualmente, para tủbos de vidro de $2,5 \mathrm{~cm}$ de diâmetro x $8,5 \mathrm{~cm}$ de altura, contendo em seu interior $2,0 \mathrm{~cm}$ de areia esterilizada (em autoclave), levemente umedecida com água destilada. Esses tubos tinham um tampão de algodão para evitar a fuga dos adultos.

\subsubsection{Adultos}

Ao emergirem os adultos, estes eram transferi dos dos tubos de vidro para gaiolas de criação (descritas no î́tem 3.1.), e "sexados" .

\subsection{BIOLOGIA EM DIFERENTES TEMPERATURAS}

Este estudo foi conduzido em camaras climatizadas reguladas para 20,25 e $30^{\circ} \mathrm{C}$, todas com umidade rela tiva e fotofase constantes, respectivamente de $60+10 \%$ e 14 horas. 


\subsubsection{Ovo}

Em cada temperatura, os ovos foram colocados em placas de Petri $(1,3 \times 10 \mathrm{~cm})$, em números variáveis, porém nunca inferior a 15 ( 4 repetições). Em cada uma das placas foram colocados $15 \mathrm{ml}$ de água destilada, onde os ovos ficavam mergulhados até a eclosão das larvas. Através de observações diárias determinou-se o período de incubação e viabilidade dos ovos.

\subsubsection{Larva}

Após a eclosão, as larvas eram transportadas - para placas de Petri contendo a dieta artificial descrita no ítem 3:2.3. , para observação da duração e viabilidade desta fase.

\subsubsection{Pupa}

Tão logo ocorria a pupação se processava a transferência das pupas para tubos de vidro $(2,5 \times 8,5 \mathrm{~cm})$. contendo na sua parte inferior $2,0 \mathrm{~cm}$ de areia esterilizada e. levemente umedecida com âgua destilada. Os tubós eram tam pados com algodão e colocados. em engradados de arame, até a emergência dos adultos. Foram observadas a duração e a via- 
bilidade pupal.

\subsubsection{Adulto}

Assim que emergiam, os adultos eram transferidos para gaiolas de criação, descritas em 3.1., mantendo-se 1 casal por gaiola, num total de 20 casais. Em cada gaiola foi colocado um receptáculo de postura, descrito no ítem 3.2.1. e alimento para adultos (Tabela 2).

TABELA 2 - Composição da dieta utilizada para criação de adultos de $A$. fraterculus.

Fermento Fleisctmann

$6,0 \mathrm{~g}$

Mel

$10,0 \mathrm{~g}$

A çúcar mascavo $25,0 \cdot \mathrm{g}$

Gevral (Baunilha) (Produto da Lederle) $25,0 \mathrm{~g}$ Levemil $1,0 \mathrm{~g}$ Açúcar branco $35,0 \mathrm{~g}$ Hidrolizado de proteína (Produto da Rhodia) $5,0 \mathrm{ml}$

Para melhor homogeneização dos componentes, primeiramente dissolveram-se os açúcares branco e mascavo em ãgua quente. Os demais componentes só foram adicionados depois que ocorreu o resfriamento dos açúcares. Uma vez prepa 
rada, essa dieta era mantida em geladeira.' Este alimento era colocado em pequenos pedaços de papel parafinado presos ao teto da gaiola com auxílio de um alfinete. Para evitar o escorrimento, este alimento era fornecido na forma pastosa.

Nesta fase foram observados: período de pré-o viposição, numero de posturas, número de ovos por fêmea por dia, número total de ovos por fêmea durante todo o período de oviposição e longevidade de machos e fêmeas.

\subsection{TABELA DE VIDA DE FERTILIDADE}

Baseando-se nos dados biológicos obtidos a $25^{\circ} \mathrm{C}$, foi confeccionada uma tabela de vida de fertilidade.

Os valores das colunas $\mathrm{x}, \mathrm{mx} e \mathrm{e}$ e os indices $T, R_{0}, r_{m}$ e $\lambda$ foram calculados segundo SILVEIRA NETO et alii (1976):

$x$ = intervalo de tempo onde foram tomadas as amostras; $m x$ = fertilidade específica (número de fêmeas que darão fêmeas, calculada tomando-se pór base a razao sexual);

$\ell x=$ taxa de sobrevivência no intervalo da amostragem.

Os indices calculados foram:

$\mathbf{T}$ = duração média de uma geraçao;

$R_{0}=$ taxa líquida de reprodução;

$r_{m}=$ capacidade de aumento em indivíduos;

$\lambda=$ razão finita de aumento. 


\title{
3.5. Temperatura base (limiar de desenvolvimento) e CONS- TANTE TÉRMICA
}

\begin{abstract}
Baseando-se nos resultados biológicos do item 3.3., o limiar de desenvolvimento ou temperatura base para a fase de ovo foi calculado pelo método do coeficiente de variação (HADDAD e PARRA, 1984). A constante térmica foi calculada pela fórmula $\mathrm{K}=\mathrm{y}(t-\mathrm{a})$, cițada por SILVEIRA NETO et alii (1976), onde: $\mathrm{K}=$ constante térmica expressa em graus dias $(G D) ; t=$ temperatura ambiente; $a=$ temperatura do limiar de desenvolvimento; $t-a=$ temperatura efetiva e $y=$ tempo exigido para completar o desenvolvimento (dias).
\end{abstract}

3.6. COMPARACÃO DE MEIOS ARTIFICIAIS PARA CRIACÃO DE LARVAS

Foram comparadas as seguintes dietas (Tabela 3):

TABELA 3 - Composição das dietas testadas para criação de larvas. de A. fraterculus.

Dieta A-(GONZALEZ et alii, 1971):

Água

$300 \mathrm{ml}$

Benzoato de sódio

$7 \mathrm{~g}$

$\mathrm{HCl}$

$25 \mathrm{ml}$

Levedura $300 \mathrm{~g}$

Pó de cenoura liofilizada

$500 \mathrm{~g}$

OBS.: $\circ$ pH foi ajustado para 3,8 
Dieta B - (Dieta utilizada no Departamento de Entomologia da ESALQ, para criação de Ceratitis capitata, sendo uma modificação daquela proposta por MAEDA et alii, 1953) :

Cenoura crua ralada

$400 \mathrm{~g}$

Levedura

$80 \mathrm{~g}$

Tetraciclina

$250 \mathrm{mg}$

Metil parahidroxibenzoato

$2,5 \mathrm{~g}$

Dieta C - (Utilizada em Gainesville, Flórida (EUA), para cria ção de $A$. suspensa - informação pessoal do Prof. Jo sé Roberto Postali Parra):

Metil parahidroxibenzoato

$2,0 \quad 9$

Benzoato de sódio

$2,0 \quad 9$

$\mathrm{HCl}$ concentrado

$8,1 \mathrm{ml}$

Formaldeído 20\%

$0,6 \mathrm{ml}$

Sacarose

$45,0 \mathrm{~g}$

Germe de trigo

$67,2 \mathrm{~g}$

Levedura

$67,2 \mathrm{~g}$

Bagacilho de cana (esterilizado)

$135,0 \quad 9$

Água

$600,0 \mathrm{mI}$

Dieta D - (Utilizada no Departamento de Entomologia

(ESÄLQ) para Anastrepha spp.) :

Agar

119

Metil parahidroxibenzoato

$1,5 \mathrm{~g}$

Sacarose

Colesterol

$40 \quad 9$

Germe de trigo

29

Sais de Wesson

$2 \mathrm{~g}$

Levedura

$30 \quad 9$

Cloridrato de colina

$30 \quad 9$

Caseína

$0,7 \mathrm{~g}$

Água

$15 \ldots \mathrm{g}$

OBS.: $\bigcirc \mathrm{pH}$ foi ajustado para 4,5 


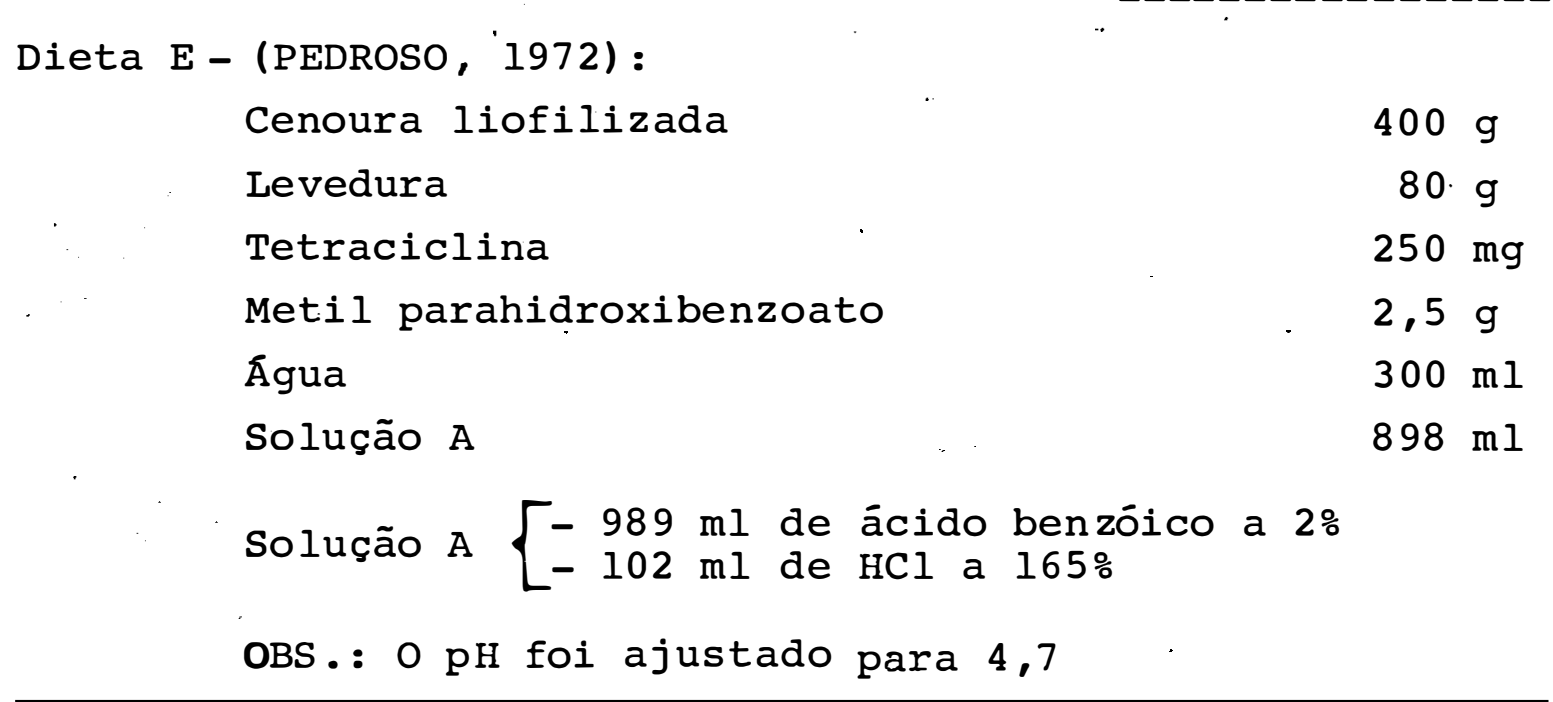

\subsubsection{Preparo das dietas}

- As placas de Petri $(I, 3 \times I 0 \mathrm{~cm})$ e os tubos de vidro $(2,5 \times 8,5 \mathrm{~cm})$, antes de receberem as dietas, foram estèrilizados em estufas a $120^{\circ} \mathrm{C}$, durante 30 minutos. Para as dietas nas quais foram necessários ajustes de $\mathrm{pH}$, usou-se um determinador de $\mathrm{pH}$ digital.

\section{Dieta A}

Em um recipiente foram colocados primeiramente os componentes em pó e em seguida os componentes líquidos, sendo o conjunto misturado até que se conseguisse uma boa homogeneização. Para a correção do pH do meio, utilizou -se uma solução de $\mathrm{NaOH}$ a 18N. As quantidades citadas foram suficientes para 20 placas de Petri. 


\section{Dietà B}

As cenouras for am lavadas em água e, em segui da, raladas com auxílio de um ralador comum. Antes de se adicionarem os demais componentes, foi retirado 0 excesso do suco da cenoura, evitando-se assim que a dieta ficasse muito aquosa. Esta receita foi suficiente para 10 pla cas de Petri.

\section{Dieta C}

o bagacilho de cana foi esterilizado em autoclave. Primeiramente foram colocados os componentes sólidos e depois os componentes líquidos e, em seguida, homoge neizados. Essas quantidades foram suficientes para is placas de Petri.

\section{Dieta D}

Primeiramente foi dissolvido o ágar em $\quad 1000$ ml de áqua aquecida e, em seguida, foram adicionados os demais componentes e misturados com auxílio de um agitador elé trico. A correção do $\mathrm{pH}$ do meio foi feita utilizando-se $\mathrm{HCl}$ a 2 N. Essas quantidades foram suficientes para 40 tubos de vidro.

\section{Dieta $E$}

Os componentes sólidos foram misturados e, em seguida, foi adicionada a água e a solução $A$, sendo o conjun 
to homogeneizado. $\mathrm{O} \mathrm{pH}$ foi ajustado para 4,7 através de $\mathrm{NaOH}$ a $18 \mathrm{~N}$. Essas quantidades foram suficientes para 10 pla cas de Petri.

\subsection{EfEITO DE DifERENTES CONDicões DE UMIDADE NA ECLOSÃo DE LARVAS}

Para verificar a necessidade ou não, do conta to direto com água para a eclosão dás larvas foi desenvolvido o presente teste, onde foram comparados os seguintes tratamentos:
A - ovos mergulhados em água de torneira $(15 \mathrm{ml} /$ placa de Petril);
B - ovos mergulhados em solução salina a 2\%;
C - ovios mantidos sobre papel de filtro umede cido;
D - ovos mantidos diretamente sobre a dieta artificial padrão (ítem 3.2.3.).

Os ovos foram retirados dos receptáculos de postura e colocadós em cada tratamento, da mesma forma como descrito em 3.2.2.

Em cada condição foram analisados 100 ovos, sendo divididos em 4 repetições de 25 ovos, mantidos em placas de Petri $(1,3 \times 10 \mathrm{~cm})$, em sala com temperatura de 25 $2^{\circ} \mathrm{C}$, umidade relativa de $60 \pm 10 \%$ e fotofase de 14 horas. Em 
cada tratamento registraram-se o período de incubação e a viabilidade.

\subsection{INFLUENCIA DA COR E TIPO DE RECEPTÁCULO NA POSTURA}

Foi utilizado o tipo convencional de local de postura (descrito em 3.2.1.) de coloração vermelha, como tra tamento padrão. Paralelamente, foram comparados dois outros substratos semelhantes a este padrão, variando-se apenas a coloração da espuma que passou a ser verde e amarela, nümeros 352 e 286 do Código Universal de Cores, Seguy (1936), res pectivamente. Um $4:$ tratamento consistiu em tingir-se uma das faces da gaiola utilizada para adultos (ítem 3.2.1.), de vermelho. Esta face era constituída de tecido (morim de algodão) tingido de vermelho (no 93 do Código Universal de Cores, SEGUY, 1936) através de um corante (utilizado em cob̈ertura de bolos) da marca "San-ei". Para tornar o tecido resistente, ele foi revestido com uma camada de vaselina:parafina na proporção de 50:50. Visando uma melhor fixação, o tecido foi mergulhado no corante dissolvido em áqua durante 15 minutos e depois posto para secar à sombra. Depois de tingido e seco, o tecido foi mergulhado na mistura de parafi na:vaselina derretida e homogeneizada, e posteriormente pos to para secar. Para coleta dos ovos, utilizou-se um pincel número 0 , retirando-os individualmente e colocando-os em uma placa de Petri contendo água de torneira. 


\subsection{INFLUENCIA DO FOTOPERIODO NO DESENYOLVIMENTO DO IN- SETO}

Utilizou-se um equipamento, proposto por PARRA et al.ii (1977), que permite compararem-se diferentes com binações de horas de luz e escuro.

Para este estudo, foram utilizadas 6 câmaras cilíndricas de $30 \mathrm{~cm}$ de altura x $30 \mathrm{~cm}$ de diâmetro, consti tuídas de chapas, com a parte superior fechada com um disco de madeira no qual estava instalada uma lâmpada fluorescente de 8 watts tipo luz-do-dia. As lâmpadas eram acionadas por relógio-de-tempo "timer", sendo possível assim regular os pe ríodos de fotófase e escotofase. A ventilação das câmaras era feita pela entrada forçada de ar, proveniente de um compressor. Com isso, a temperatura interna das câmaras era de $25 \pm 1^{\circ} \mathrm{C}$ (Tabela 4).

Em cada uma das câmaras foram colocadas 100 larvas em placas de Petri $(1,3 \times 10 \mathrm{~cm})$ contendo a dieta C (ítem 3.6.),divididas em 4 repetições. Diariamente eram fei tas observações, e assim que havia a transformação em pupas era feita à transferência individual das mesmas para tubos de vidro $(2,5 \times 8,5 \mathrm{~cm})$, contendo na parte inferior, uma camada de areia fina esterilizada e levemente úmedecida.

Atravês de observações diārias, determinaram -se: duração e viabilidade das fases larval e pupal. A umi- 
dade relativa da sala de estudos era de $60 \pm 10 \%$.

TABELA 4 - Combinações de fotofase e escotofase para o estudo da influência do fotoperíodo na duração e viabilidade das fases larval e pupal de A. fratercuZus.

\begin{tabular}{ccc}
\hline & Fotof ase & Escotofase \\
\hline $\mathrm{T}_{1}$ & 24 & 0 \\
$\mathrm{~T}_{2}$ & 0 & 24 \\
$\mathrm{~T}_{3}$ & 6 & 18 \\
$\mathrm{~T}_{4}$ & 12 & 12 \\
$\mathrm{~T}_{5}$ & 14 & 10 \\
$\mathrm{~T}_{6}$ & 18 & 6 \\
\hline
\end{tabular}

\subsection{ANÁLISE ESTATISTICA}

Para análise estatística os dados de viabilidade foram transformados para arc.sen $\sqrt{\circ}$.

Os dados obtidos em todos os experimentos rea lizados foram submetidos à análise de variância, sendo as mé dias comparadas pelo teste de. Tukey ao nível de 5\% de probaḅilidade. Para comparação das médias no teste de influência de cores como substrato de postura (3.8.), foi empregado o 
teste $\mathrm{x}^{2}$ (qui-quadrado) ao nível de 5\% de probabilidade. Com os dados de longevidade de adultos de $A$. fraterculus foi fei ta a aplicação do modelo de distribuição de Weibull, a fim de se obter a longevidade média e o modelo de sobrevivência de adultos (SGRILLO, 1982). 


\section{RESULTADOS E DISCUSSÃO}

\subsection{IDENTIFI I CACÃOO DA ESPECIE}

Os espécimens coletados foram identificados como Anastrepha fratereulus (wied., 1830).

4.2. BIOLOGIA DE Anastrepha fraterculus (WIED,; 1830) EM DIFERENTES DIETAS ARTIFICIAIS

\subsubsection{Larva}

Das cinco dietas pesquisadas para a criação de A. fraterculus, somente em três delas as larvas completaram o seu desenvolvimento (Tabela 5). A dieta que mais se sobressaiu foi aquela à base de bagacilho de cana, germe de trigo e levedura (Tabela 3 - dieta C), usada como dieta pa- 
drão para o estudo da biologia de $A$, fratérculus. Esta dieta promoveu um encurtamento do ciclo e maior viabilidade la val, vindo a seguir a dieta à base de cenoura crua ralada e levedura (Tabela 3 - dieta B). Embora nesta segunda dieta tenha sido observado um alongamento da fase larval, a viabilidade foi comparável àquela obtida na dieta que proporcionou o melhor desenvolvimento desta fase. Apesar da dieta à base de germe de trigo, caseína e levedura (Tabela 3 - dieta D) ter possibilitado a complementação da fase larval, houve um alongamento deste período de 9,71 dias em relação à melhor dieta, e uma baixíssima viabilidade, au seja de 1\% (Tabela 5 e Figura 1). Nas dietas à base de cenoura liofilizada e levedura (Tabela 3 - dietas A e E) nenhuma larva comple tou o seu desenvolvimento.

A duração obtida na dieta $B$ foi superior àque le valor registrado por GONZALES et alii (1971) que, trabalhando com dieta semelhante, obtiveram uma duração da fase larval para $A$. fraterculus de 8 dias à temperatura de $27^{\circ} \mathrm{C}$. Por outro lado, o valor obtido na' presente pesquisa ficou dentro da faixa relatada por BAKER (1945), que utilizando uma dieta natural à base de fatias de ameixa registrou, para A. fraterculus, uma duração do período larvas variável de 10 a 21 dias para temperaturas de 17 a $27,5^{\circ} \mathrm{C}$. 
TABELA 5 - Duração e viabilidade da fase larval de A.fraterculus em diferentes dietas artificiais. Temperatu ra: $25 \pm 0,5^{\circ} \mathrm{C}$; UR: $60 \pm 10 \%$ e fotofase: 14 horas.

\begin{tabular}{l} 
Dietas \\
\cline { 2 - 6 } \\
\cline { 2 - 6 }
\end{tabular}

\subsubsection{Pupa}

Na fase de pupa foi mantida a mesma tendência registrada na fase larval. Assim, houve uma redução na dura ção da fase pupal e maior viabilidade nas pupas provenientes de larvas criadas na dieta $C$, à base de bagacilho de cana, germe de trigo e levedura (Tabela 6).

A viabilidade pupal, embora baixa, foi maior na dieta $C$ em relação à dieta $B$, não havendo emergência na dieta D (Tabela 6 e Figura 1). 
A duração registrada na melhor dieta

dias) foi inferior àquela referida por GONZALES et al.ii (1971) em dieta de cenoura em pó e levedura, pois estes autores obtiveram uma duração média de 12 dias a $27^{\circ} \mathrm{C}$.

TABELA 6 -Duração e viabilidade da fase pupal de A. fratercu Zus em diferentes dietas artificiais. Temperatura: $25 \pm 0,5^{\circ} \mathrm{C}$. UR: $60 \pm 10 \%$ e fotofase: 14 horas.

\begin{tabular}{|c|c|c|c|c|c|}
\hline \multirow{2}{*}{ Dietas } & \multicolumn{4}{|c|}{ Duração (dias) } & \multirow{2}{*}{$\begin{array}{l}\text { Viabi- } \\
\text { lidade } \\
\quad(\%)\end{array}$} \\
\hline & $\mathrm{n}$ & Média ${ }^{1}$ & $s(\bar{x})$ & $I \cdot V \cdot 2$ & \\
\hline $\begin{array}{l}\text { B (cenoura crua ralada } \\
\text { e levedura) }\end{array}$ & 800 & $17,42 \mathrm{~b}$ & 0,27 & $17-20$ & $15,90 \mathrm{a}$ \\
\hline $\begin{array}{l}\text { C (bagacilho de cana, } \\
\text { germe de trigo e le- } \\
\text { vedura) }\end{array}$ & 1000 & $9,69 a$ & 0,20 & $9-11$ & $22,03 \mathrm{a}$ \\
\hline $\begin{array}{l}\text { D (germe de trigo, ca- } \\
\text { seina e levedura) }\end{array}$ & 20 & - & - & - & 0,00 \\
\hline
\end{tabular}

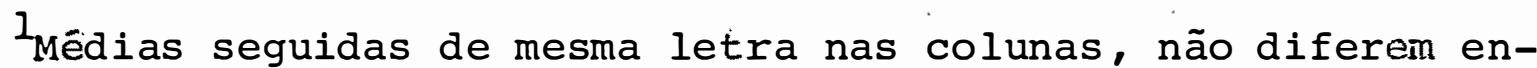
tre si, pelo teste de Tukey, ao nível de 5\% de probabilidade.

2Intervalo de variação.

número de pupas.

Pode-se constatar que, embora a dieta $D$ seja nutricionalmente mais rica em termos protéicos en relação às dietas B eC, ela não proporcionou um bom desenvolvimento de A. fraterculus, o que pode ser devido às características físi cas do meio artificial, ọ mesmo devido a um desbalanceamento entre os componentes da dieta (PARRA, 1979). Em linhas ge rais, pode-se constatar que as dietas nutricionalmente mais adequadas promoveram um encurtamento dociclo do inseto (Figura 1). 


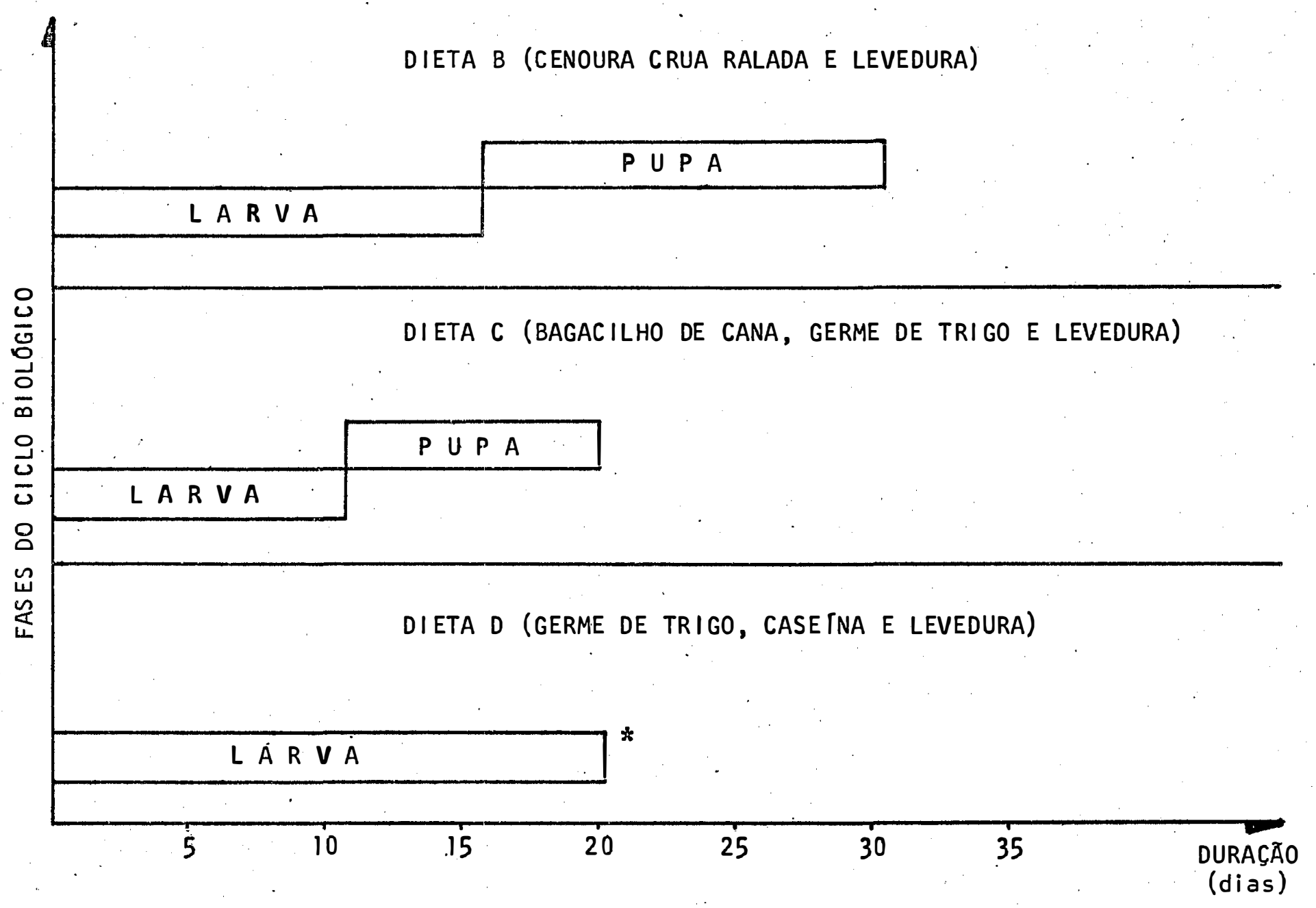

FIGURA 1 -Duração das fases larval e pupal de A. fraterculus em dietas artificiais. Temperatura: $25 \pm 0 \% 5^{\circ} \mathrm{C}$; UR: $60 \pm 10 \%$ e fotofase: 14 horas. * Não houve emergência na dieta $D$. 


\subsection{BIOLOGIA DE A. fraterculus EM DIFERENTES TEMPERATU- RAS}

\subsubsection{Ovo}

A temperatura a fetou o período de incubação, o qual decresceu com $O$ incremento térmico na faixa de $20-25^{\circ} \mathrm{C}$ (Tabela 7).

Não houve diferença estatística com relação à duração entre as temperaturas de 25 e $30^{\circ} \mathrm{C}$. Os dados obtidos na presente pesquisa a 25 e $30^{\circ} \mathrm{C}$ se aproximam daqueles registrados por BAKER (1945), que obteve a $30^{\circ} \mathrm{C}$ um período de incubação de 50 horas $(2,08$ dias) para $A$. fraterculus e aos de GONZALES et alii (1971) que obtiveram, para o mesmo inseto a $27^{\circ} \mathrm{C}$, um período de incubação de 3 dias. Pelos resulta dos obtidos com relação à viabilidade, pode-se concluir -que a temperatura mais adequada para o desenvolvimento embrionário de $A$. fraterculus é a de $25^{\circ} \mathrm{C}$. Com rélação a este parâmetro, não houve diferença entre os resultados obtidos a 20 e $30^{\circ} \mathrm{C}$ (Tabela 7). 
TABELA 7 - Duração é viabilidade da fase dè ovo de $A$. frate $\underline{r}$ culus em diferentes temperaturas. UR: $60 \pm 10 \%$ e fotofase: 14 horas.

\begin{tabular}{|c|c|c|c|c|c|}
\hline \multirow{2}{*}{$\begin{array}{l}\text { Temperatura } \\
\left(\mathrm{O}^{\mathrm{C}}\right)\end{array}$} & \multicolumn{4}{|c|}{ Duração } & \multirow{2}{*}{$\underset{(\%)}{\text { Viabilidade }}$} \\
\hline & $\mathrm{n}$ & Média ${ }^{1}$ & $s(\bar{x})$ & $I . V .2$ & \\
\hline 20 & 2000 & $4,77 \mathrm{a}$ & 0,15 & $4-6$ & $40,76 \mathrm{~b}$ \\
\hline 25 & 2000 & $2,85 \mathrm{~b}$ & 0,15 & $2-4$ & $59,33 \mathrm{a}$ \\
\hline 30 & 2000 & $2,86 \mathrm{~b}$ & 0,15 & $2-4$ & $44,89 \mathrm{~b}$ \\
\hline
\end{tabular}

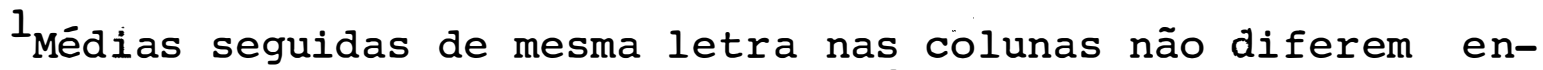
tre si, pelo teste de Tukey, ao nível de 5\% de probabilidade.

2Intervalo de variação.

$\mathrm{n}_{\mathrm{Número}}$ de ovos.

\subsubsection{Larva}

Embora os estudos referentes à fase larval de A. fraterculus tenham sido iniciados nas temperaturas . de 20,25 e $30^{\circ} \mathrm{C}$, apenas nas duas primeiras houve desenvolvimen to do inseto. A $30^{\circ} \mathrm{C}$, ocorria freqüentemente ressecamento e contaminação da dieta. Na tentativa de contornar o problema do ressecamento, aumentou-se a quantidade de.água na dieta, o que fazia com que as larvas aí colocadas não se alimentassem .

Nas temperaturas em que o inseto completou a fase larval, o desenvolvimento foi mais rápido a $25^{\circ} \mathrm{C}$, cujo valor diferiu significativamente da média registrada a $20^{\circ} \mathrm{C}$ 
(Tabela 8), confirmando ser esta temperatura a mais adequada para criação de $A$. fraterculus.

Os resultados obtidos se encontram na faixa registrada por BAKER (1945) que, embora trabalhando com dieta natural à base de fatias de ameixas, registrou, para a du ração do período larval, valores de 10 a 21 dias para temperaturas de 17 a $27,5^{\circ} \mathrm{C}$. Os maiores valores de viabilidade re gistrados a $25^{\circ} \mathrm{C}$, mostraram ser esta temperatura a mais adequada para esta espécie de mosca-das-frutas (Figura-2).

TABELA 8 - Duração e viabilidade da fase larval de A. frater culus em temperaturas de 20 e $25^{\circ} \mathrm{C}$. UR: $60 \pm 10 \%$ e fotofase: 14 horas.

\begin{tabular}{|c|c|c|c|c|c|}
\hline \multirow{2}{*}{$\begin{array}{l}\text { Temperatura } \\
\text { (OC) }\end{array}$} & \multirow[b]{2}{*}{$\mathrm{n}$} & \multicolumn{3}{|c|}{ Duração (dias) } & \multirow{2}{*}{$\begin{array}{c}\text { Viabilidade } \\
\left(\frac{0}{0}\right)\end{array}$} \\
\hline & & Médial & s. $(\bar{x})$ & I.V. 2 & \\
\hline 20 & 800 & $18,7 \quad b$ & 0.30 & $15-23$ & $42,24 a$ \\
\hline 25 & 1000 & $13,95 \mathrm{a}$ & 0,30 & $10-16$ & $61,66 \mathrm{~b}$ \\
\hline
\end{tabular}

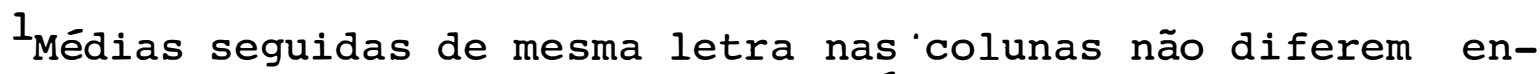
tre si, pelo teste de Tukey, ao nível de 5\% de probabilidade.

2 Intervalo de variação.

$\mathrm{n}_{\text {Número de larvas. }}$

\subsubsection{Pupa}

A obtenção dos dados relativos à duração

e 
viabilidade nesta fase só foi possível a $25^{\circ} \mathrm{C}$, pois a $20^{\circ} \mathrm{C}$ houve mortalidade total das pupas por problemas ocorridos nas câmaras climatizadas.

A duração, média a $25^{\circ} \mathrm{C}$ foi de 10 dias, com um intervalo de variação (I.V.) de 9 a 11 dias, enquanto a viabilidade foi de 21,6\%: BAKER (1945) obteve, para a duração desta fase, valores variáveis entre 10,5 e 35 dias em tempera turas de 17,5 a $30^{\circ} \mathrm{C}$, enquanto GONZALES et alii (1971), trabalhando a $27^{\circ} \mathrm{C}$, encontraram para a duração do período pupal, um valor médio de 12 dias.

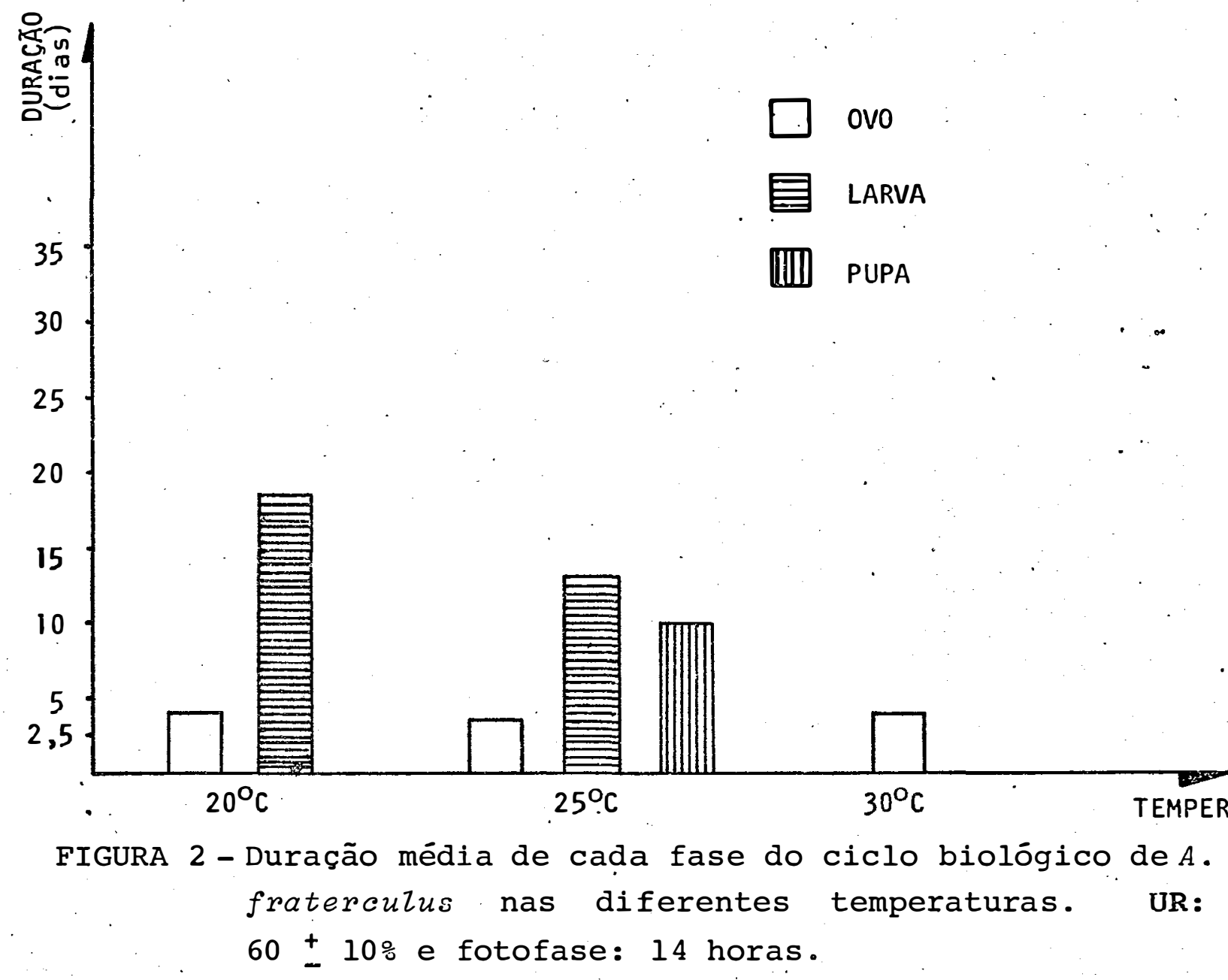




\subsubsection{Adulto}

Constatou-se que a longevidade dos machos foi significativamente maior que a das fêmeas (Tabela 9). Após a morte da fêmea, o macho continuava sua atividade no interior da gaiola, alimentando-se normalmente. Os resultados de lon gevidade para os machos seguiram a distribuição de Weibull, o mesmo não ocorrendo para fêmeas (Figura 3 ).

GONZALES et alii (1971) obtiveram para as fêmeas da referida espécie, uma longevidade de 85 dias, estando próximo ao resultado obtido nesta pesquisa que foi de 87,8 dias. O resultado de longevidade de fêmeas obtido foi superior àquele registrado por LOPES (1986), que para $A$. fra terculus, obteve, em cruzamentos coletivos, uma longevidade para fêmeas de 69 dias.

TABELA 9 - Longevidade média de adultos de $A$. fratericulus. Temperatura: $25 \pm 0,5^{\circ} \mathrm{C}$; UR: $60 \pm 10 \%$ e fotofase: 14 horas.

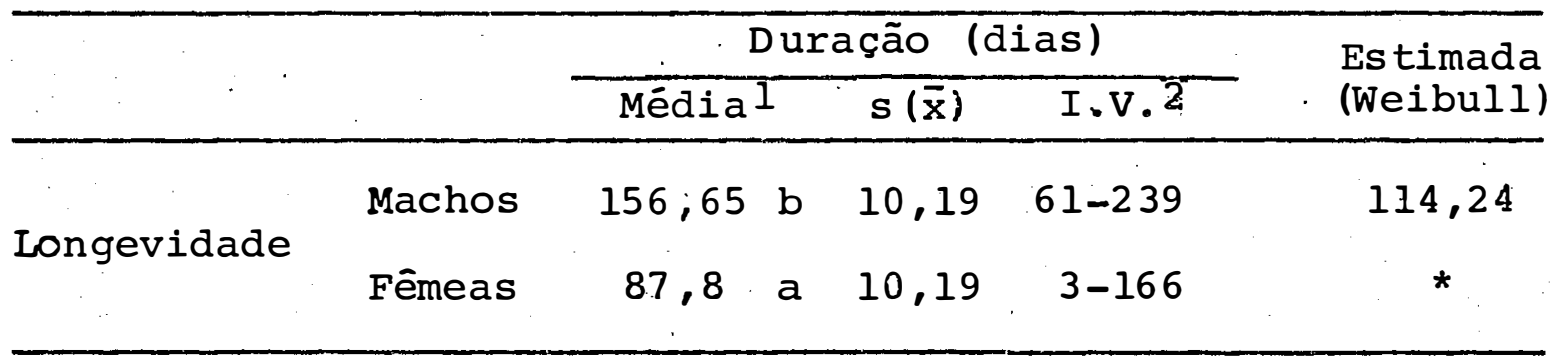

lMédias seguidas de mesma letra nas colunas não diferem entre si, pelo teste de Tukey, ao nível de 5\% de probabilida2 Intervalo de variação.

* Não calculada para fêmeas, por não ter sido significativo. 


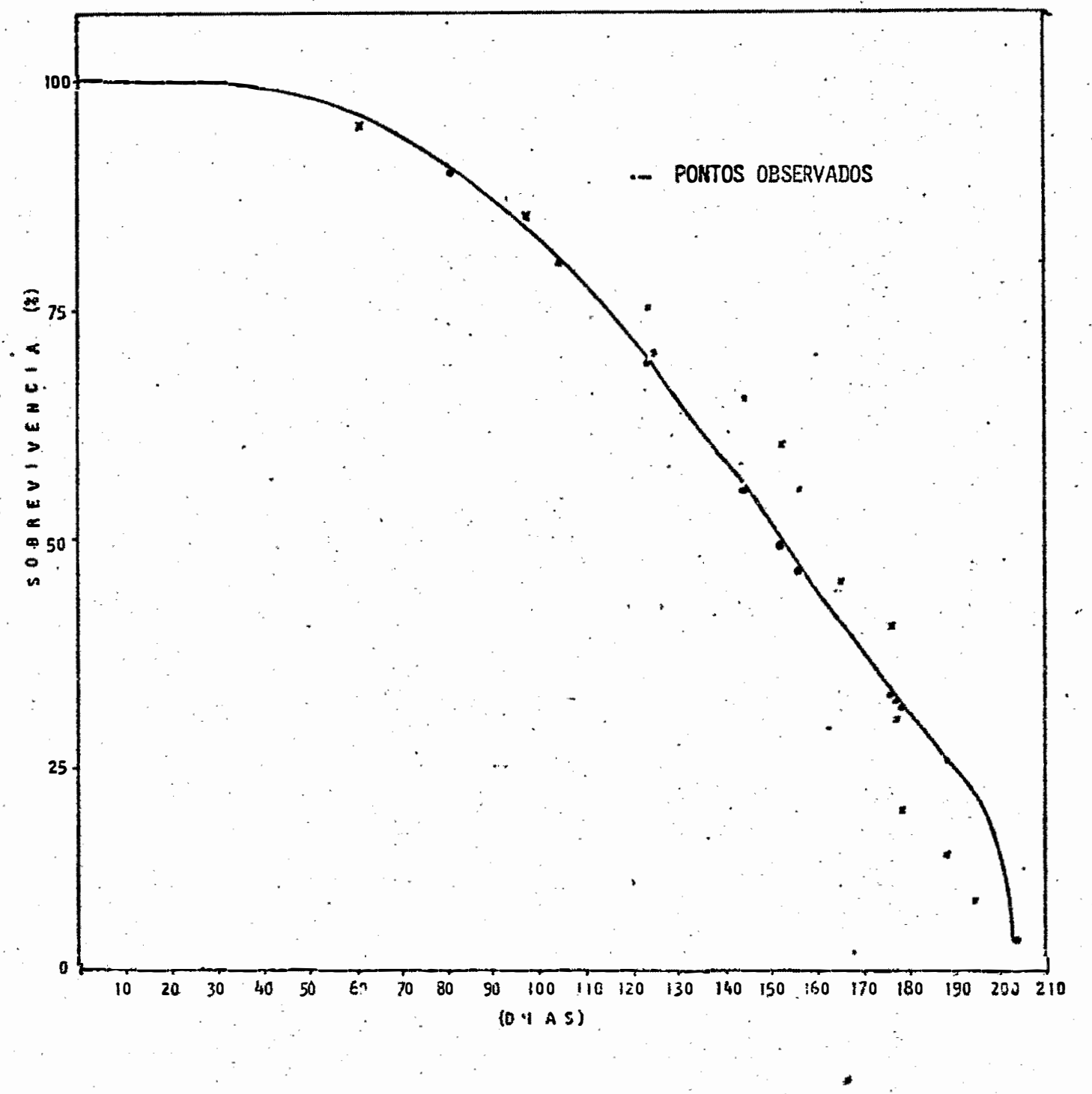

FIGURA 3 - Curva de longevidade de machos de $A$. fraterculus baseada na distribuição de. Weibull. 
o numero total de ovos por fêmea (394,2 ovos) (Tabela 10), obtido nesta pesquisa, se aproximou daquele registrado por GONZALEZ et alii (1971) para $A$. fraterculus, que foi de 415 ovos/fêmea e foi superior aos resultados de LOPES (1986) para a mesma espécie $(312,9$ ovos/fêmea). O segundo autor obteve uma viabilidade para ovos de $A$. fraterculus de $65 \%$, próxima àquela obtida no presente trabalho $(66,9 \%)$.

BALIU e MALAVASI (1985), trabalhando com $A$. fraterculus obtiveram, a partir do segundo mês de oviposição, $28 \pm 4$ ovos por fêmea por dia, resultạdo este coinciden te com os encontrados nesta pesquisa, o qual foi, em média de 25,16 ovos por fêmea por dia. Os resultados do numero médio de ovos colocados durante o período de oviposição, bem como a viabilidade correspondente encontram-se nas Figuras 4 e. 5 respectivamente.

o ritmo de postura indicou que, no início da oviposição, o número de ovos é maior, havendo um decréscimo com a idade das fêmeas, mostrando que elas diminuem a fecundidade em função do tempo. A mesma tendência foi observada com relação à viabilidade. Após a última postura, as fêmeas ainda permanecem vivas por um período médio de 7,7 dias.

o período de pré-oviposição observado (Tabela 10) (22,2 dias), foi superior àquele determinado por BALIU e MALAVASI (1985) para cruzamentos coletivos, o qual foi de 15 dias, e inferior ao registrado pelos mesmos autores para 
cruzamentos individuais (30 dias). Segundo LOPES (1986), O período médio de pré-oviposição para $A$. fraterculus é de 30,1 dias. Os resultados obtidos no período de pré-oviposição não coincidiram com os de GONZALES et a $2 i i$ (1971) que obtiveram, para essa espécie, um período de 9 dias.

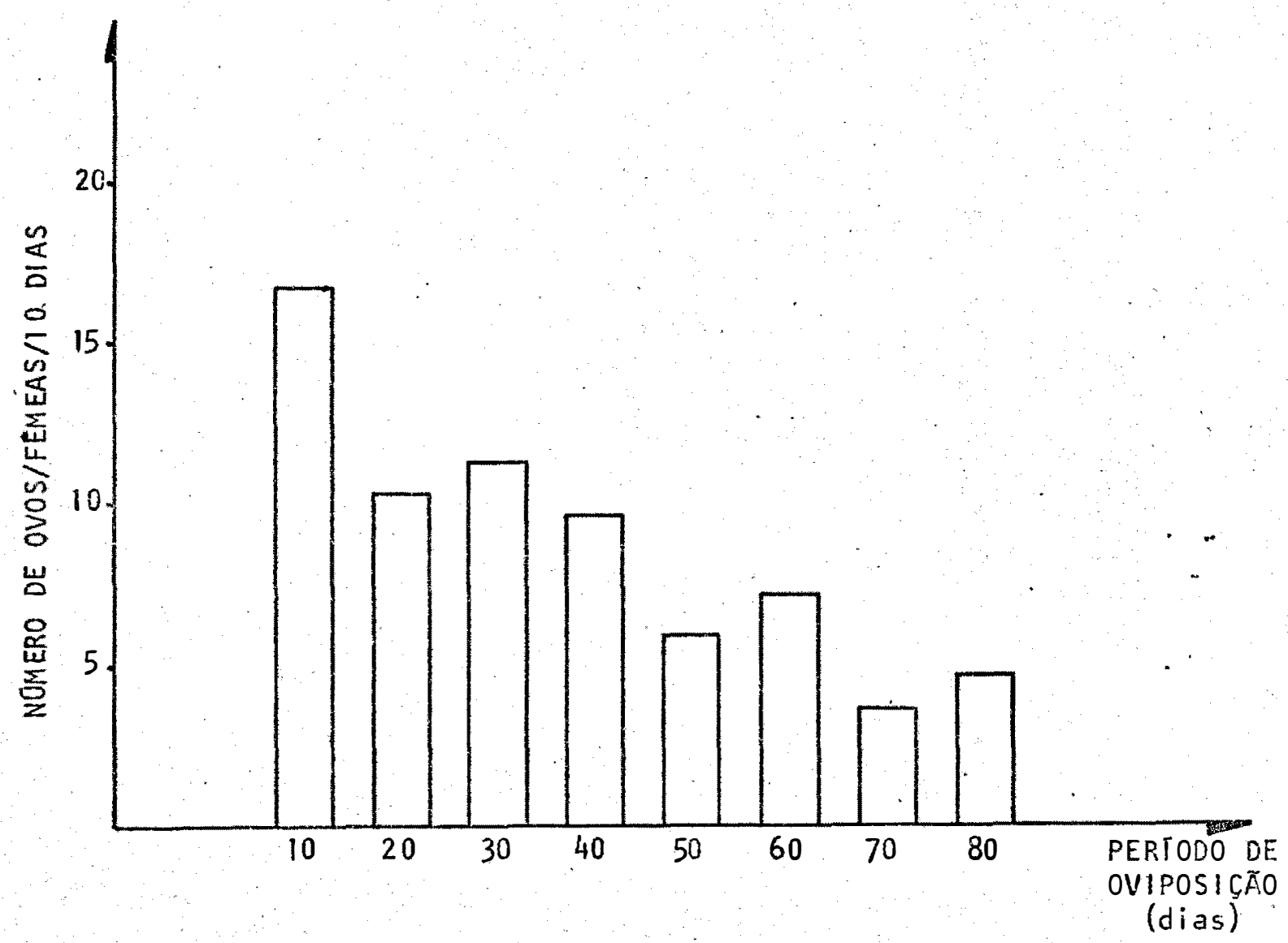

FIGURA 4 - Nümero médio de ovos colocados por A. fraterculus. Temperatura: $25 \pm 0,5^{\circ} \mathrm{C}$; UR: $60 \pm 10 \%$ e fotofase: 14 horas. 


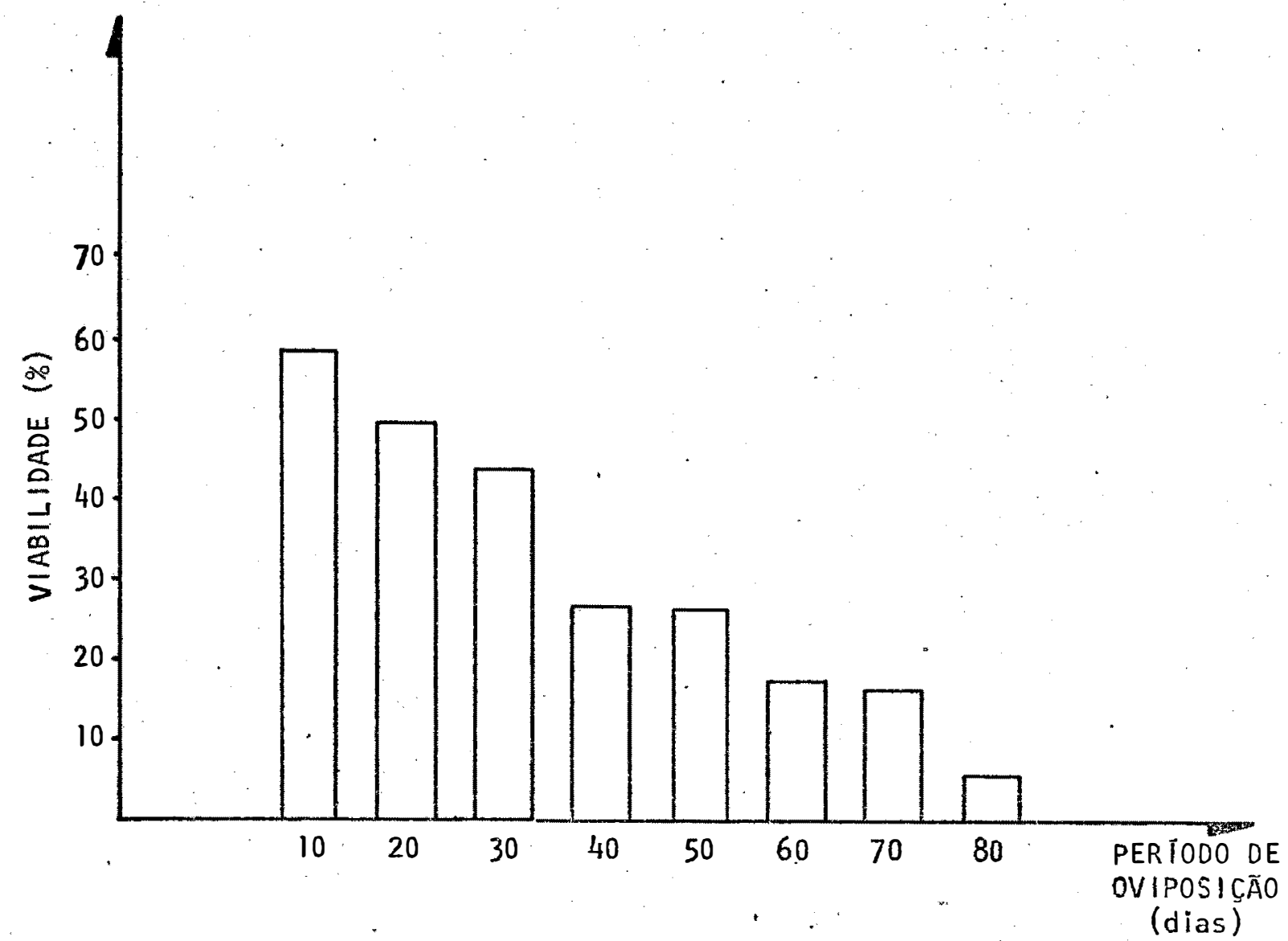

FIGURA 5 - Viabilidade média de ovos de A. fraterculus duran te o período de oviposição. Temperatura: $25 \pm$ $0,5^{\circ} \mathrm{C} ; \mathrm{UR}: 60 \pm 10 \%$ e fotofase: 14 horas.

o período de oviposição (Tabela 10), foi mui to próximo daquele obtido pór BALIU e MALAVASI (1985) que registraram, para $A$. fraterculus um período de 80 dias; porém, a duração na presente pesquisa foi superior àquela obtị da por.LOPES (1986) e GONZALEZ et alii (1971). 
Pode-se constatar, no presente trabalho, que os ovos obtidos apresentaram uma redução no período de incubação e aumento na viabilidade em relação àqueles ovos prove nientes de pupas obtidas de frutos coletados no campo. Este aumento pode ser devido à proporção entre machos e fêmeas (1:1) mantida neste teste de laboratório, situação esta que provavelmente proporcionou melhores condições de acasalamento em relação àquela utilizada para insetos provenientes dos frutos, onde os indivíduos eram mantidos em regime coletivo, sem controle da proporção entre os sexos. Talvez, neste segundo caso, a própria liberação excessiva de feromônio sexual possa ter prejudicado o acasalamento de $A$. fraterculus. Desta forma, sugerem-se estudos neste sentido, visando deter minar a proporção ideal de machos e fêmeas, para criação de laboratório, bem como o número adequado de indivíduos por re cipiente de criação pois, segundo PETERS e BARBOSA (1977), es te número foi colocado em recipiente de criação de uma forma inadequada (excesso ou mesmo falta) o que poderá levar a alterações morfológicas, biológicas e comportamentais de insetos.

Através dos resultados da tabela de vida de fertilidade (Tabela 11), observa-se que, embora a mortalidade dos estágios imaturos tenha sido elevada (Tabelas 5 e 6) $(7,9 \%)$, a taxa de reprodução foi alta. Assim, a taxa líquida de reprodução $\left(R_{0}\right)$ indicou que a cada geração ocorrerá um aumento de 16,57 vezes da população,sendo adictonadas 1,2975 ( $\lambda$ ) fêmeas que darão fêmeas à população de A. fraterculus. 
Desta forma, como ò comportamento biológico do inseto em condições de campo é desconhhecido, é provável que na natureza ocorra uma alta mortalidade dos estágios imaturos, pois os resultados obtidos indicam, em função da fertilidade, que a dieta artificial utilizada é nutricionalmente adequada para esta espécie. Apesar disto, sugere-se que sejam realizadas pesquisas no sentido de ajustar as proporções dos nutrientes desta dieta, a qual poderá se tornar no futuro, uma dieta apropriada para $A$. fraterculus.

Devem ser estimuladas pesquisas como comparações de novas dietas artificiais, contendo fontes protéicas variáveis e que sejam analisados outros aspectos como características físicas da dieta (textura, estrutura, forma de fornecimento, consistência, etc.) além de fatores abióticos que poderão interferir no desenvolvimento do inseto.

TABELA 10 - Períodos de pré-oviposição, oviposição, incubação, fecundidade dos adultos e viabilidade de ovos dẹ A. fratercuzus. Temperatura: $25 \pm 0,5^{\circ} \mathrm{C}$; UR: $60 \pm$ $10 \%$ e fotofase: 14 horas.

\begin{tabular}{lccc}
\hline Aspectos biológicos & Duração & (dias) & Viabilidade \\
\cline { 2 - 3 } & Média & I.V.I & (o) \\
\hline Período de pré-oviposição & 22,20 & $15-35$ & - \\
Período de oviposição & 79,10 & $0-150$ & - \\
Número de ovos/fêmea/dia. & 25,16 & $0-39,8$ & - \\
Número de ovos/fêmea/total & 394,20 & $0-979$ & - \\
Período de incubação & 2,71 & $1-3$ & 66,9 \\
\hline
\end{tabular}

Intervalo de variação. 
TABELA 11 - Tabela de vida de fertilidade de A. fraterculus. Temperatura: $25 \pm 0,5^{\circ} \mathrm{C} ; \mathrm{UR}: 60 \pm 10 \%$ e fotofa se: 14 horas.

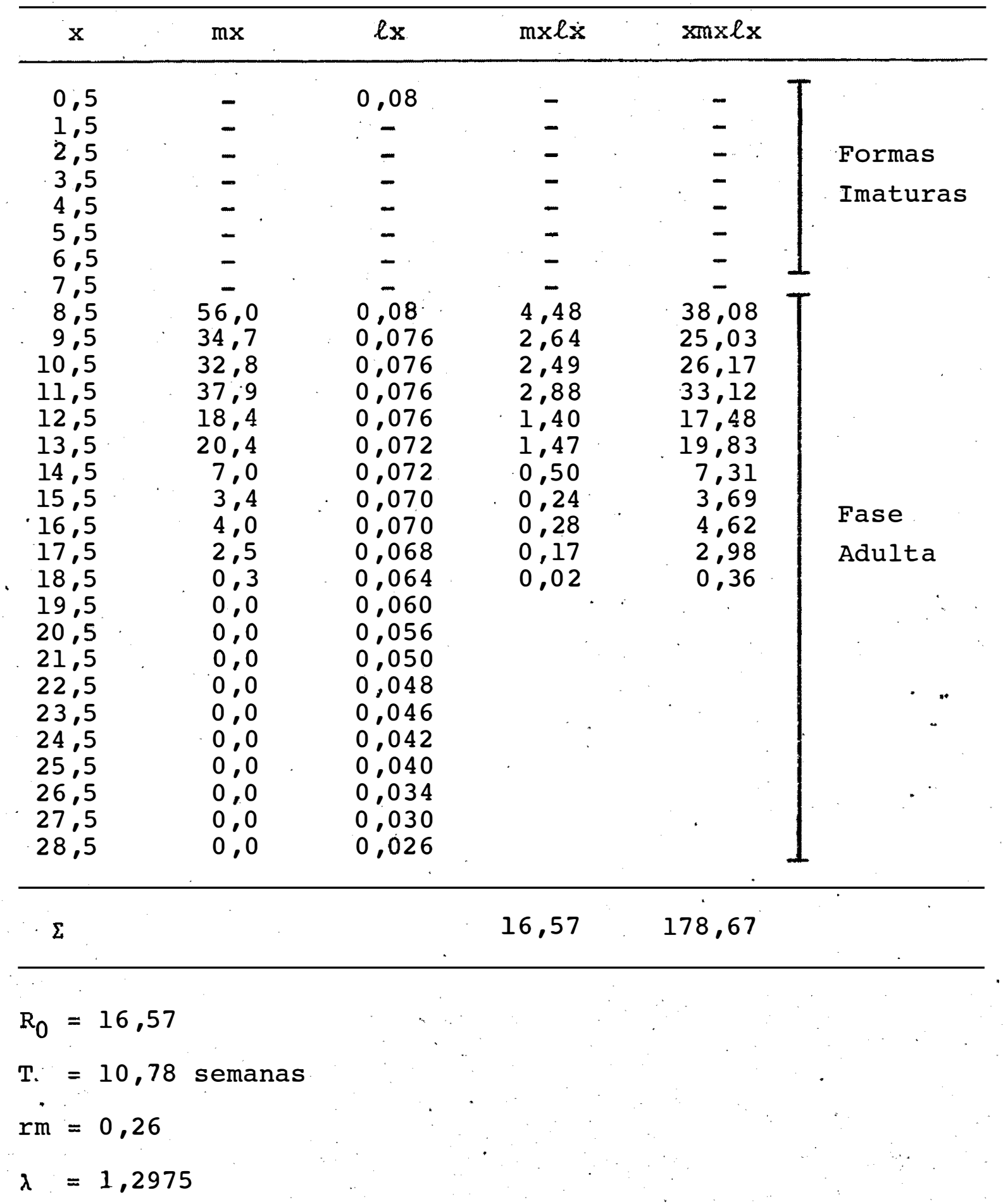


4.3.5. Determinação das exigênclas térmicas de ovos de A. frateroulus

A determinação da temperatura base llimiar tér mico inferior) só foi realizada para ovos, já que, apenas pa ra esta fase, foram obtidos dados para as três temperaturas inicialmente estudadas.

Os resultados obtidos (Tabela 12 ) indicam ser de $6,3^{\circ} \mathrm{C}$ a temperatura base para os ovos de $A$. fraterculus, os quais exigem para completar o desenvolvimento embrionário $61,26 \mathrm{GD}$.

TABELA 12 - Temperatura base (Tb) e constante térmica (K) da fase ovo de $A$. fraterculus. Temperaturas de 20 , 25 e $30^{\circ} \mathrm{C}$; UR: $60 \pm 10 \%$ e fotofase: 14 horas.

\begin{tabular}{ccc}
\hline Fase & $\mathrm{Tb}\left({ }^{\circ} \mathrm{C}\right)$ & $\mathrm{K}(\mathrm{GD})$ \\
\hline ovo & 6,3 & 61,26 \\
\hline
\end{tabular}

Convém salientar que para a determinação de Tb e $\mathrm{K}$ é recomendável que se tenha, no mínimo, 4 valores experimentais (HADDAD e PARRA, 1984). Como na presente pesqui sa foram obtidos resultados a partir de apenas 3 valores, su gerem-se testes experimentais para comprovação deste limiar 
térmico inferior para $A$. fraterculus.

\subsection{COMPARAÇ̃̃O DE SUBSTRATOS EM DIFERENTES CORES PARA POSTURA DE A. fratercuzus}

A cor preferida para oviposição por A. frate $\underline{r}$ culus foi a vermelha, (n̊ 93) do Código Universal de Cores, SEGUY (1936), cujos valores diferiram estatisticamente daqueles registrados nas cores amarela, (n 286) do Código Universal de Cores, SEGUY (1936), que apresentou valores intermediários, e verde, (no 352) do Código Universal de Cores, SÉGUY (1936), na qual foram registrados os menores valores (Tabela 13). Traba 'lhos de GONZALEZ et alii (1971) e LOÚRENÇO et alii (1977) mos tram esta preferência da mosca pela cor vermelha, sendo que LOPES (1986) usou como substrato para postura de A. fratercu lus dispositivos plásticos em semi-esferas tingidos com anilina vermelha.

Os resultados não foram satisfatórios quando se testou tecido "voil" tingido de vermelho, nᄋ 93 do Código Universal de Cores, SÉGUY (1936), e recoberto com uma mis tura de vaselina e parafina, pois a fêmea preferiu ovipositar em outros locais da gaiola. Os poucos ovos colocados sobre o referido tecido não foram viáveis provavelmente devi do ao ressecamento. A técnica com utilização de esponjas se mostrou satisfatória para obtenção de ovos de A. fraterculus 
e, dentre as vantagens deste método, o não ressecamento de ovos é uma das mais importantes. Entretanto, estudos devem ser conduzidos no sentido de se substituir o "Parafilm" por um produto de baixo custo, sobretudo quando o objetivo for a produção de um grande número de insetos.

TABELA 13 - Efeito de diferentes cores na postura de A. fraterculus. Temperatura: $25 \pm 1^{\circ} \mathrm{C} ;$ UR: $60 \pm 10 \% \mathrm{e}$ fotofase: 14 horas.

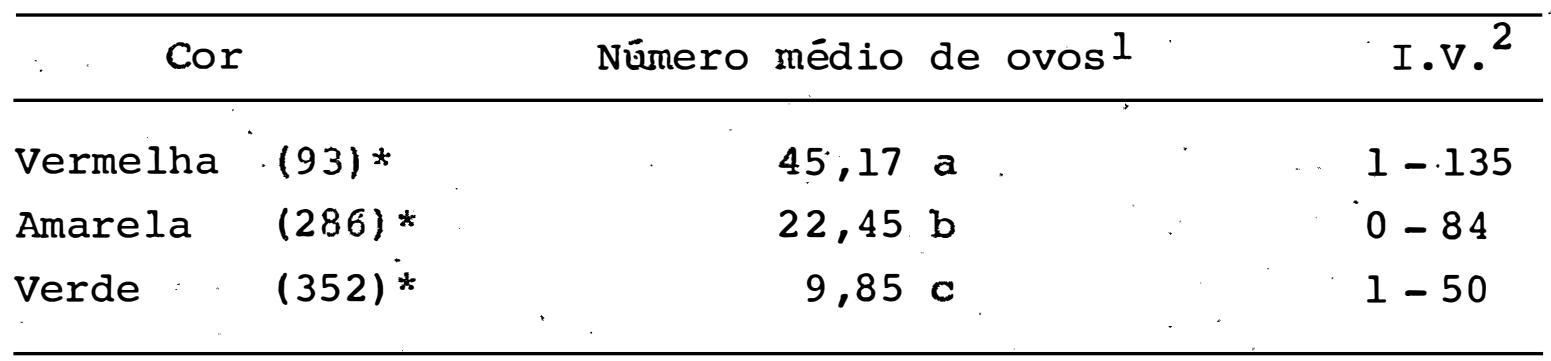

${ }^{1}$ Médias seguidas de mesma letra nas colunas não diferem entre si, pelo teste $x^{2}$ (Qui-quadrado), ao nivel de 5\% de probabilidade.

2 Intervalo de variação.

*Número referente ao Código Üniversal de Cores, SEGur (1936).

\subsection{EFEITO DE DIFERENTES SUBSTRATOS NO DESENVOLVIMENTO EMBRIONÁRIO DE $A$. fraterculus}

A menor duração para o períodó de incubação foi registrada quando os ovos foram colocados diretamente na água, sendo os valores médios obtidos neste tratamento estatisticamente inferiores aos demais (Tabela 14). A maior via- 
bilidade obtida nesta condição, em relação aos demais tratamentos, evidenciou, ao lado do menor período registrado, a necessidade do contato da água para o bom desenvolvimento em brionário de $A$. fraterculus. No tratamento com solução salí na, embora houvesse o contato com a água, ocorreu algum efei tó deletério, não identificado, especialmente na viabilidade (Tabela 14). Embora nos tratamentos, papel de filtro umedecido e ovos colocados diretamente na dieta, a umidade fosse próxima à saturação, não houve. contato direto dạ água com os ovos, o que, aparentemente, prejudicou o crescimento e desenvolvimento do embrião.

TABELA 14 - Período de incubação e viabilidade de ovos de $A$. fraterculus, em diferentes substratos. Temperatura: $25 \pm 0,5^{\circ} \mathrm{C}$; UR: $60 \pm 10 \%$ e fotofase: 14 ho ras.

\begin{tabular}{|c|c|c|c|c|c|}
\hline \multirow{2}{*}{ Tratamentos } & \multicolumn{4}{|c|}{ Duração (dias) } & \multirow{2}{*}{$\begin{array}{c}\text { Viabi- } \\
\text { lidade } \\
\left(\frac{0}{3}\right)\end{array}$} \\
\hline & $\mathrm{n}$ & Médial & $s(\bar{x})$ & I.V. 2 & \\
\hline Somente água & 150 & $2,33 a$ & 0,12 & $2-4$ & $60 \mathrm{a}$ \\
\hline Solução salina a $2 \%$ & 150 & $2,50^{\circ} \mathrm{b}$ & 0,15 & $2-4$ & $40 \mathrm{~b}$ \\
\hline Papel de filtro umedecido & 150 & $2,73 \mathrm{~b}$ & 0,14 & $2-4$ & $46 \mathrm{~b}$ \\
\hline Diretamente na dieta & 150 & $3,63 \mathrm{~b}$ & 0,15 & $3-5$ & $38 \mathrm{~b}$ \\
\hline
\end{tabular}

Médias seguidas de mesma letra nas colunas não diferem entre si, pelo teste de Tukey, ao nível de 5\% de probabilidade. . Intervalo de variação.

$\mathrm{n}_{\text {Número de ovos. }}$ 

CRIACÃO DE $A \cdot$ fratercuzus

\subsubsection{Larva}

De acordo com a Tabela 15 e Figura 6, verifica-se que houve uma melhor aceitação das larvas quando colocadas na dieta normal (sem adição de água posteriormente à preparação do meiol pois houve uma redução na duração do período larval, sugerindo que a quantidade de água colocada na dieta é um fator muito importante no desenvolvimento do inseto. Assim, ocorreu um prolongamento da fase larval,quan do a quantidade de água foi excessiva.. Por outro lado, as viabilidades larvais foram semelhantes nos meios testados, e videnciando que, para as condições de estudo, a umidade não afetou a mortalidade das larvas.

TABELA 15 - Duração e viabilidade da fase larval de A.f.rater culus em dieta artificial com diferentes teores de umidade. Temperatura: $25 \pm 0,5^{\circ} \mathrm{C}$; UR: $60 \pm$ $10 \%$ e fotofase: 14 horas.

\begin{tabular}{|c|c|c|c|c|c|}
\hline \multirow{2}{*}{ Tratamentos } & \multicolumn{4}{|c|}{ Duração (dias) } & \multirow{2}{*}{$\begin{array}{c}\text { Viabi- } \\
\text { lidade } \\
(\%)\end{array}$} \\
\hline & $\mathrm{n}$ & Média ${ }^{1}$ & $s(\bar{x})$ & $I . V \cdot{ }^{2}$ & \\
\hline $\begin{array}{l}\text { Dieta. com adição de } 1 \\
\text { de água. }\end{array}$ & 150 & $20,38 \mathrm{~b}$ & 0,56 & $11-43$ & 31,3 a \\
\hline $\begin{array}{l}\text { Dieta sem adição de } 15 \mathrm{ml} \\
\text { de água. }\end{array}$ & 150 & $15,97 \mathrm{a}$ & 0,59 & $11-22$ & 28,7 a \\
\hline
\end{tabular}

l Médias seguidas de mesma letra nas colunas nãodiferem entre si, pelo teste de Tukey, ao nível de 5\% de probabilidade.

2 Intervalo de variação.

$\mathrm{n}_{\mathrm{Número}}$ de larvas. 


\subsubsection{Pupá}

A umidade não interferiu na duração da fase pupal (Tabela 16 e Figura 7). Por outro lado, o excesso de água provocou uma redução na viabilidade da fase pupal, ratị ficando a existência de um ótimo de umidade para criação de A. fraterculus.

TABELA 16 - Duração e viabilidade da fase pupal de A. frater culus em dieta artificial com diferentes teores de umidade. Temperatura: $25 \pm 0,5^{\circ} \mathrm{C}$; UR: $60 \pm$ $10 \%$ e fotofase: 14 horas.

\begin{tabular}{|c|c|c|c|c|c|}
\hline \multirow{2}{*}{ Tratamentos } & \multicolumn{4}{|c|}{ Duração (dias) } & \multirow{2}{*}{$\begin{array}{c}\text { Viabi- } \\
\text { lidade1 } \\
\left(\frac{0}{6}\right)\end{array}$} \\
\hline & $\mathrm{n}$ & Média $^{1}$ & $s(\bar{x})$ & $I \cdot V \cdot{ }^{2}$ & \\
\hline
\end{tabular}

Dieta com adição de $15 \mathrm{ml} \quad 150 \quad 11,33$ a $\quad 0,70 \quad 10-14 \quad 12,76$ a de água.

Dieta sem adição de $15 \mathrm{ml} \quad 150$. $11,7.0$ a $0,54 \quad 10-13 \quad 23 ; 25 \mathrm{~b}$ de água.

1 Médias seguidas de mesma letra nas colunas não diferem entre si, pelo teste de Tukey, ao nível de 5\% de probabilidade.

Intervalo de variação.

número de pupas. 


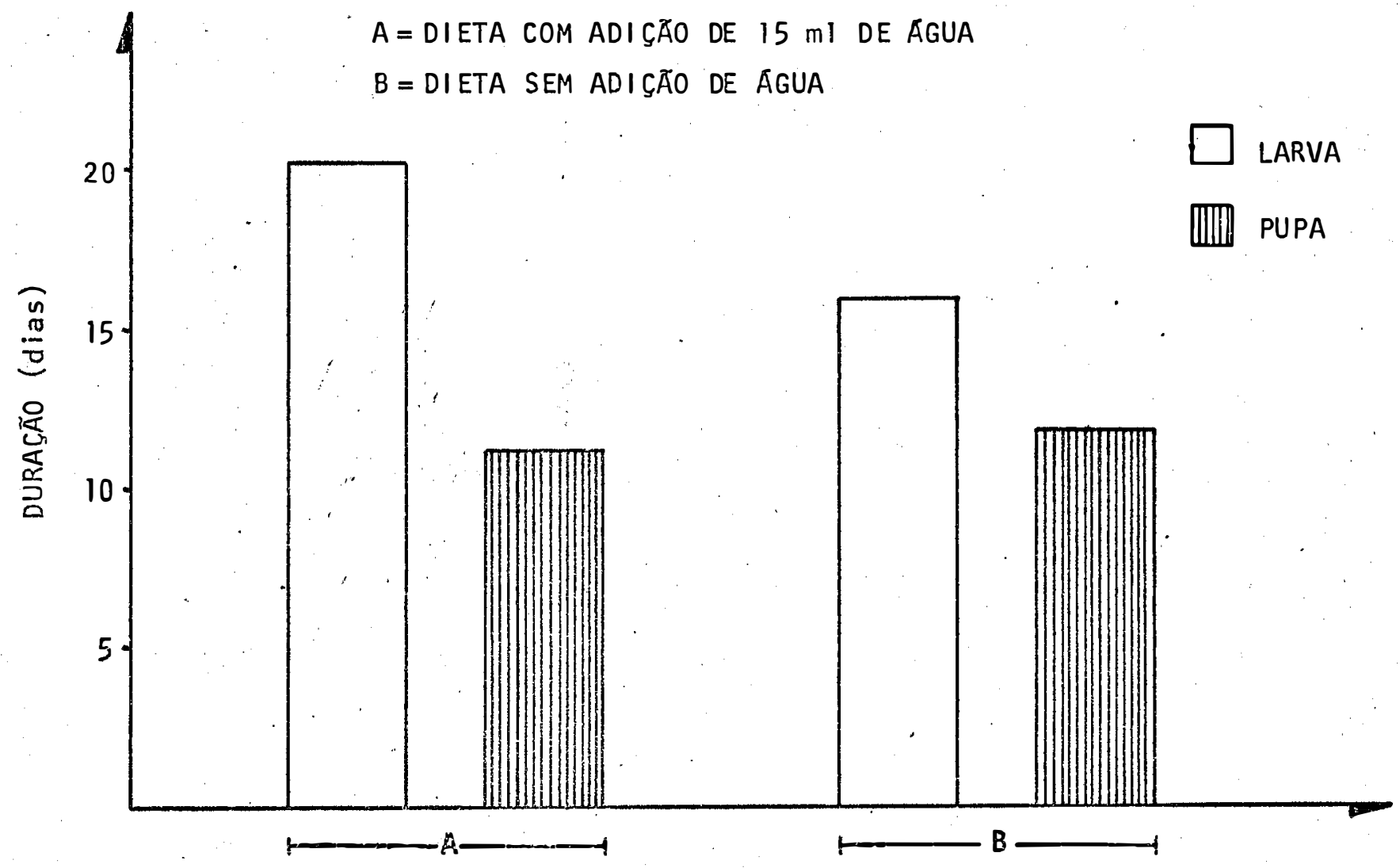

FIGURA 6 - Duração das fases larval e pupal de A. fraterculus em dieta artificial com e sem adição de água. Temperatura: $25 \pm 1^{\circ} \mathrm{C} ;$ UR: $60 \pm 10 \%$ e fotofase: 14 horas. 


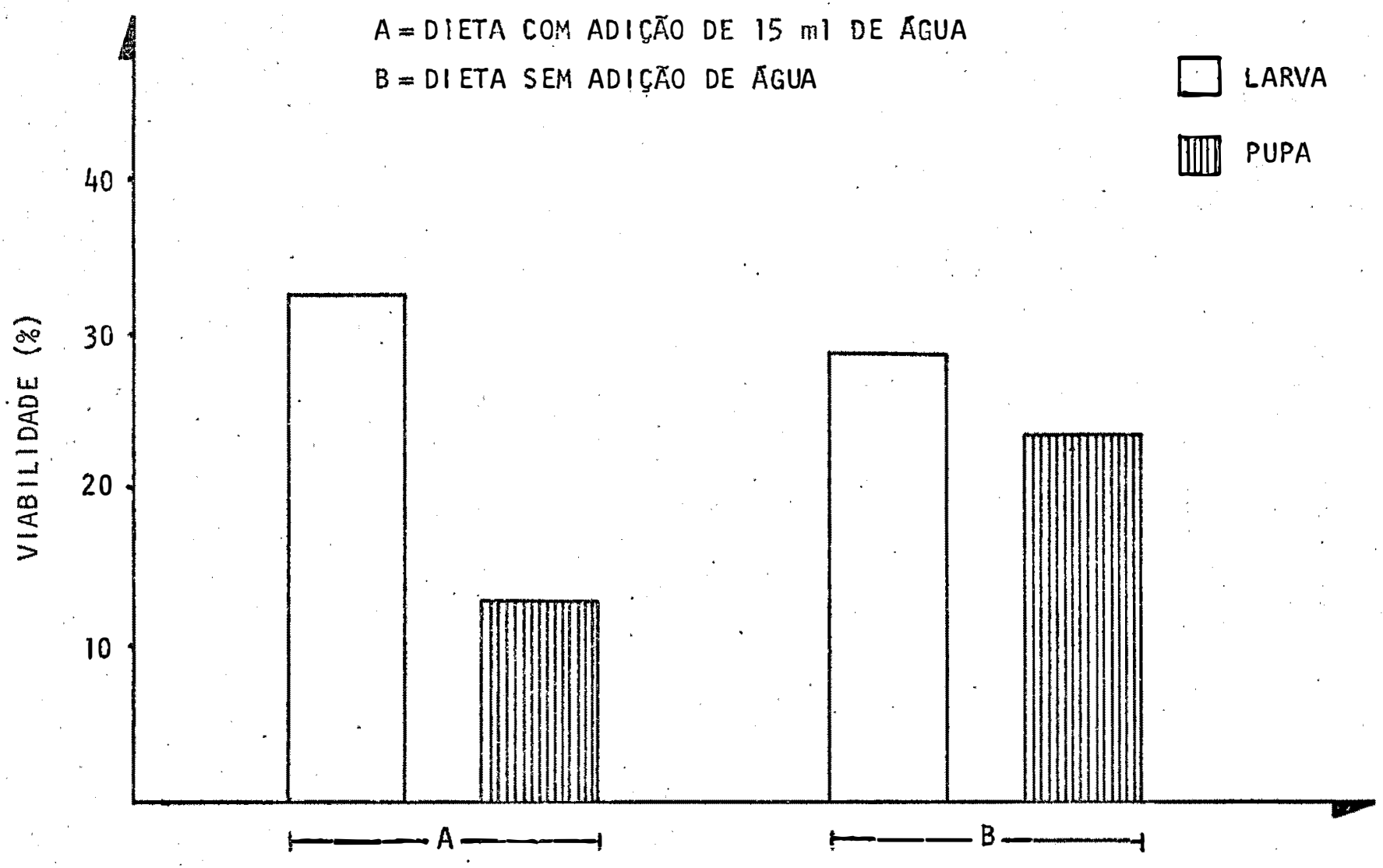

FIGURA 7 - Viabilidade das fases larval e pupal de A. fraterculus em dieta arti ficial com e sem acição de ägua. Temperatura: $25 \pm 1^{\circ} \mathrm{C}$; UR: $60 \pm 10 \%$ e fotofase: 14 horas. 


\subsection{EFEITO DO FOTOPERIODO NA DURACÃO DOS PERIOdOS LARVAL E PUPAL DE A. fratercuzus}

\subsubsection{Larva}

Pelos resultados obtidos (Tabela 17), embora não tenha havido diferença significativa na duração da fase larval entre as várias combinações de fotofase e escotofase empregadas, observou-se diferença na viabilidade, tendo as combinações $6: 18$ e 14:10 (fotofase : escotofase) sido as. mais adequadas, pois possibilitaram maiores,valores (Tabela 17) .

TABELA 17 - Duração e viabilidade da fase larval de A. frater culus em diferentes fotoperiodos." Temperatura: 25 $\pm 1^{\circ} \mathrm{C}$ e UR: $60 \pm 10 \%$.

\begin{tabular}{|c|c|c|c|c|c|c|c|}
\hline \multicolumn{2}{|c|}{ Tratamentos } & \multicolumn{4}{|c|}{ Duração (dias) } & \multirow{2}{*}{\multicolumn{2}{|c|}{$\begin{array}{c}\text { Viabili } \\
\text { dadel } \\
(\%)\end{array}$}} \\
\hline Fotofase & Escotofase & $\bar{n}$ & Médial & $s(\bar{x})$ & $\mathrm{I} . \mathrm{V} \cdot \mathrm{2}^{2}$ & & \\
\hline 24 & 0 & 200 & $27,44 a$ & 1,99 & $14-30$ & 30 & C \\
\hline 0 & 24 & 200 & $23,00 \mathrm{a}$ & 1,95 & $12-30$ & 45 & $\mathrm{~b}$ \\
\hline 6 & 18 & 200 & $20,68 \mathrm{a}$ & 1,35 & $12-28$ & 64 & $\mathrm{a}$ \\
\hline 12 & 12 & 200 & $21,82 a$ & 1,84 & $12-30$ & 34 & c \\
\hline 14 & 10 & 200 & $20,82 a$ & 1,60 & $13-30$ & 61 & a. \\
\hline 18 & 6 & 200 & 23,69 a & 1,78 & $13-30$ & 36 & c \\
\hline
\end{tabular}

${ }^{1}$ Médias seguidas de mesma letra nas colunas não diferem entre si, pelo teste de Tukey, ao nível de 5\% de probabilidade. 2

Intervalo de variação.

número de larvas. 


\subsubsection{Pupa}

Houve influência do fotoperíodo na duração da fase pupal, a qual foi menor no tratamento $6: 18$, o fotoperío do 24:0 provocou um alongamento desta fase (Tabela 18). Con siderando-se as viabilidades da fase pupal, elas foram maiores no tratamento $14: 10$ e 18:6. Analisando-se os dados da fase larval e pupal de uma forma conjunta e tendo em vista que a duração da fase pupal obtida no fotoperiodo 6:18 não diferiu dos demais tratamentos (Tabela 18), o fotoperiodo 14:10 pode ser considerado o mais adequado para criação de A. fratercuzus.

TABELA 18 - Duração e viabilidade da fase pupal de A. fraterculus em diferentes fotoperíodos. Temperatura: 25 $\pm 1^{\circ} \mathrm{C}$ e UR: $60 \pm 10 \%$.

\begin{tabular}{|c|c|c|c|c|c|c|}
\hline \multicolumn{2}{|c|}{ Tratamentos } & \multicolumn{4}{|c|}{ Duração (dias) } & \multirow{2}{*}{$\begin{array}{c}\text { Viabili } \\
\text { dadel } \\
(\%)\end{array}$} \\
\hline Fotofase & Escotofase & $\mathrm{n}$ & Médial & $s(\bar{x})$ & I.V. ${ }^{2}$ & \\
\hline 24 & 0 & 200 & $19,33 \mathrm{a}$ & 1,19 & $14-33$ & $19,0 \mathrm{~b}$ \\
\hline 0 & 24 & 200 & $18,07 \mathrm{ab}$ & 1,14 & $14-30$ & $28,8 \mathrm{~b}$ \\
\hline 6 & 18 & 200 & $14,33 \mathrm{~b}$ & 2,37 & $14-18$ & $29,6 \mathrm{~b}$ \\
\hline 12 & 12 & 200 & $15,10 a b$ & 0,94 & $14-16$ & $8,8 \mathrm{c}$ \\
\hline 14 & 10 & 200 & $15,25 \mathrm{ab}$ & 1,19 & $14-18$ & $40,0 \mathrm{a}$ \\
\hline 18 & 6 & 200 & $16,60 a b$ & 1,06 & $14-30$ & 41,6 a \\
\hline
\end{tabular}

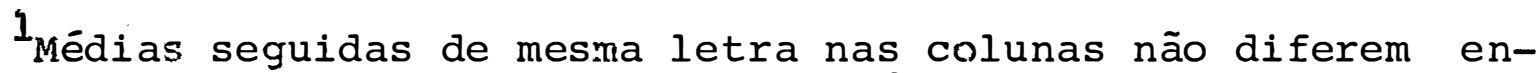
tre sí, pelo teste de Tukey, ao nível de 5\% de probabilidade.

Interi io de variação.

$\mathrm{n}_{\text {Nümero de pupas. }}$ 


\section{CONCLUSÕES}

Baseando-se nos resultados obtidos na presente pesquisa, pode-se concluir:

- A dieta artificial à base de bagacilho de cana, germe de trigo e levedura é promissora para criação de Anastrepha fraterculus (Wied., 1830), muito embora tenha proporcionado uma baixa viabilidade total.

- I temperatura de $25^{\circ} \mathrm{C}$ é a mais favorável para criação de A. fraterculus.

- A longevidade dos machos a $25^{\circ} \mathrm{C}$ é significativamente maior do que a das fëmeas.

- A capacidade de postura e a viabilidade dos ovos decrescem com a idade das fêmeas. 
- Os valores da taxa líquida de reprodução e da razão finita de aumento atestam a adequação nutricional da dieta à base de bagacilho de cana, germe de trigo e levedura.

- A temperatura base para a fase de ovo de A. fraterculus é de $6,3^{\circ} \mathrm{C}$, com uma constante térmica de 61,26 GD.

- A cor vermelha (n९ 93) do Código Universal de Cores, SÉguY (1936), é a mais adequada para substrato de postura de $A$. fraterculus.

- Há necessidade do contato do ovo direto com a água para e- closão de larvas de A. fratérculus.

- O excesso de ãgua na dieta artificial prejudica o desenvol vimento de $A$. fraterculus.

- A combinação 14:10 (fotofase:escotofase) é a mais adequada para criação de $A$. fraterculus em laboratório. 


\section{LITERATURA CITADA}

ARRIGONI, E. de B., 1984. Dinâmica populacional de moscasdas-frutas (Diptera-Tephritidae) em três regiões do Estado de São Paulo. Piracicaba, ESALQ/USP, 163p. (Tese de Doutoramento) .

AZEVEDO, E.M.V.M. e J.R.P. PARRA. Influência da umidade em 2 tipos de solo na emergência de Ceratitis capitata (Wied., 1824). Pesquisa Agropecuária Brasileira, Brasília (no prelo)

BAKER, A.C.; W.E. STONE; C.C. PLUMER A M. MC PHAIL, 1944. A review of studies on the mexican fruit fly and related mexican species. Miscellaneous Publications of the United States Department of Agricultural. Washington, $\underline{331}: 155 p$. 
BAKER, E.W., 1945. Studies on the Mexican fruit fly known as Anastrepha fraterculus. Journal of Economic Entomology, College Park. 38(1):95-100.

BALIU, M.B. e A. MALAVASI, 1985. Oviposição de Anastrepha fraterculus (Diptera, Tephritidae) em laboratório. In: Resumos 37ạ Reunião Anual da Sociedade Brasileira para o Progresso da Ciência, Brasília. p.728.

BATEMAN, M.A., 1972. The ecology of fruit flies. Annual Review of Entomology. Palo Alto. 17:493-518.

BATEMAN, M.A., 1976. Fruit flies. In: De LUCCHI, V.L. ed. Studies in biological control. Cambridge, University Press. p:11-49.

BURK, T., 1983. Behavioral ecology of mating in: the Caribbean fruit fly, Anastrepha suspensa (Loew). The Flórida Entomologist. Gainesville, 66:330-340.

CAUSSE, R., 1974. Etude d'um rythme circadien du comportenent de pré nyinfase chez Ceratitis capitata Wiedmann (Diptire Trypetidae). Annales de Zoologie Ecologie Animale. Paris, $\underline{6}(4): 475-498$. 
CHRISTENSON, L. D. e. R.H. FOOTE, 1960. Biology of fruit flies. Annual Review of Entomology. Palo Alto, $\underline{5}: 171-$ 192 .

CYTRYNOWICZ, M.; J.S. MORGANTE e H.M.L. de SOUZA, 1982. Visual respounses of South American fruit flies, Anastrepha fraterculus, and Mediterranean fruit flies, Ceratitis capitata, to colored rectangles and spheres. Environmental Entomology. College Park, $11(6): 1202-1210$.

DARBY, H.H. e E.M. KAPP, 1933. Observations on the thermal death points of Anastrepha Zudens (Loew)... Technical Bulletin. 'United States Departament of Agriculture, Washington, $(400): 1-19$.

DELANQUE, P., 1955. Contribuition a l'etude de l'élevege de Ceratitis capitata Wied.' Methode et apareils perme tzant l'élevege: de la mouche des fruits de saison. Annuals Service Botanic Tunisie. 28:23-32.

FEHN, L.M., 1977. Levantamento da ocorrênci.a de moscas-das -frutas, Diptera:Tephritidae e Lonchaeidae, em pessegueiro na área metropolitana de Curitiba e região de Iratí Paraná. Curitiba, UFPr, 172 p. (Dissertação de Mestrado) 
FINNEY, G.L., 1956. A fortified carrot medium for massculture of the oriental fruit fly and certain others tephritids. Journal of Economic Entomology. College Park, $49: 134$.

FĹTTERS, N.E., 1964. The effect of photoperiod, light intensity, and temperature on population, oviposition and fertility of the Mexican fruit filies. Journal of Economic Entomology. College Park, $57(6): 811-812$.

FOOTE, R.H., 1967. Family Tephritidae. In: A catalogue of the Diptera of the Americas South of the United States. Departamento de Zoologia, Secretaria da Agricultura. são Paulo, 57:1-91.

FRIAS, D.L.; A: MALAVASI e J.S. MORGANT'E, 1984. Field observations of distribuition and activites of Rhagoletis conversa (Diptera:Tephritidae) on two hosts in nature Annals of the Entomological Society of America. Colum bùs; 77 :

GALLO, D.; O. NAKANO; S. SILVEIRA NETO; R.P.L. CARVALHO; G. C. de BATISTA; E. BERTI FILHO; J.R.P. PARRA, R.A. ZZUCCHI e S.B. ALVES, 1978. Manual de entomologia agrícola. São Paulo, Ceres, 53lp. 
GOMES, P., 1973. Fruticultura brasileira. São Paulo, Nobel. $446 \mathrm{p}$.

GONZALEZ, J.G.; C.V. VARGAS e B. JARAP, 1971. Estudios sobre la àplicación de la técnica de machos estériles en el con trol de la mosca sudamericana de la fruta Anastrepha fraterculus (Wied.). Revista Peruana de Entomologia. Lima, $\underline{14}(1): 66-85$.

HADDAD, M.L. e J.R.P. PARRA, 1984. Métodos para estimar os limites térmicos e a faixa ótima de desenvolvimento das. diferentes fases do ciclo evolutivo dos insetos. Piracicaba, FEALQ. 12p. (Série Agricultura e Desenvolvimento).

. HERRERA, J. e L.E. VINAS, 1977. "Moscas de fruta" (Dipt. Tephritidae) em mangoes de Chulucanas, Piura. Revista Peruana de Entomologia. Lima, 20(11):107-114.

IHERING, H. VON, 1901. Laranjas bichadas. Revista de. Agricultura. $6: 179$.

KAMASAKI, H.; R. SUTTON; D.F. LOPEZ e A. SELHIME, 1970. Laboratory culture of the Caribbean fruit fly, Anastrepha. suspensa, in Florida: "Annals of the Entomological Society - of America. College Park, 63(3):639-641.

KECK, C.B., 1951. Effect of temperature on development and activity of the Melon fly. Journal of Economic Entomolo gY. College Park, 44 (6):1001-1003. 
LANDOLT, P.I. e J. HENDRICHS, 1983. Reproductive behaviour of the papaya fruit fly, Toxotrypana curvicauda Gerstaecker (Diptera:Tephritidae). Annals of the Entomological Society of America. College Park, 76:413-417.

LAUDÉHO, Y.; C. LIAROPOULOS e M. CANARD, 1978. Etude, pendant la période automnale, dư rythme de sortie hors des fruits des larves du dernier áge de la mouche de l'olive Dacus oleae (Gmel.) (Diptera; Typetidae). Annales de Zoologie Ecologie Animale. Paris, $10(1): 37-50$.

LOPES, R:M., 1986. Desenvolvimento ovariano:e aspectos reprodutivos de Anastrepha fraterculus (Diptera:Tephritidae). São Paulo, Instituto de Biociências da USP. 96p. (Disser tação de Mestrado).

LOURENÇO, M.C.F.; J.S. MORGANTE e R.M. ZANEIATO, 1977. Anas trepha fraterculus (Wied.) (Diptera:Tephritidae): oviposi ção preferencial em frutas artificiais de diferentes co res. In: Resumos da 29ạ Reunião Anual da Sociedade Brasi leira para o Progresso da Ciência. Curitiba-PR, p.708.

MALAVASI, A., 1977. Aspectos da biologia populacional e ge nética de Anastrepha (Diptera:Tephritidae). São Paulo, Instituto de Biociências da USP. 144p. (Tese de Doutora mento) . 
MALAVASI, A.; J.S. MORGANTE e R.A. ZUCCHI, 1980. Biologia de "moscas-das-frutas" (Diptera:Tephritidae). I: lista de hospedeiros e ocorrência. Revista Brasileira de Biologia. Rio de Janeiro, $\underline{40}(1): 9-16$.

MALAVASI, A., 1984. Estudos de duas espécies crípticas do gênero Anastrepha (Diptera, Tephritidae). São Paulo, Ins tituto de Biociências da USP, 189p. (Tese de Livre-Docên cia).

Mc PHAIL, M. e F.E. GUIZA, 1956. An oviposition medium for the Mexican fruit fly. Journal of Economic Entomology . College Park, $\underline{40: 44}$.

MESSENGER, P.S. e N.E. FLITTERS, 1958. Effect of constant temperature environment on the egg stage of three species of Havaian fruit flies. Annals of the Entomological Society of America. College Park, 51(2):109-119.

MITCHELL, W.C.; C.O. ANDREW; K.S. HAGEN; R.A. HAMILTON; E.J. HARRIS; K.L. MAEHLER e R.H. RHODE, 1977. Međiterranean fruit fly and its economic impact on Central America Countries and Panamá. Berkeley, University of California, $189 \mathrm{p}$. 
NAKAGAWA; S.; R.J. PROKOPY; T.T. WONG; J.R. ZIEGLER, S. M. MITCHELL; T. URAGO e E.J. HARRIS, '1978. Visual orientation of Ceratitis capitata flies to fruit models. Entomologia Experimentalis et Applicata. Amsterdam, 24:193-198.

NÁSCIMENTO, A.S. do, 1980. Dinâmica populacional de moscas -das-frutas (Dipterá-Tephritidae) no Recôncavo Baiano. Pi racicaba, ESALQ/USP, 110p. (Dissertação de Mestrado).

PARRA, J.R.P., 1979. Biologia dos insetos. Piracicaba, ESALQ, 383p. (mimeografado).

PARRA, J.R.P.; S. SILVEIRA NETO; P. KASTEN JUNIOR e W.B. CRÓ сомо, 1977. Equipamento para estudar a influência do fotoperíodo no desenvolvimento de insetos. Anais da Sociedade Entomológica do Brasil. Jaboticabal, $\underline{6}(2): 318$ 320 .

PARRA, J.R.P.; R.A. ZUCCHI e S. SILVEIRA NETO, 1982. Flutua ção populacional e atividade diária de vôo da mosca-do-Me diterrāneo em cafeeiros "Mundo Novo". Pesquisa Agrope cuária Brasileira. Brasília, 17(1):985-992.

PAVAN, O.H.O., 1978. Estudos populacionais de moscas-dos frutos (Diptera:Tephritidae e Lonchaeidae). São Paulo , Instituto de Biociências da USP. 99p. (Tese de Doutoramento). 
PEDROSO, A.S. dos, 1972. Dados bionômicos de Ceratitis capitata Wied., 1824 (Diptera:Tephritidae) obtidos em laboratório em regime de dieta artificial. Piracicaba , ESALQ/USP, 127p. (Tese de Doutoramento).

PELEG, B.A. e R.H. RHODE, 1967. New methods in mass rearing of the Mediterranean fruit fly in Costa Rica. Journal of Economic Entomology. College Park, $\underline{60}(5): 1460-1461$.

PEREZ, C.À., 1983. Efeito de produtos químicos esterilizan tes sobre Ceratitis capitata (Wiedemann, 1824) (Diptera : Tephritidae) seus simbiontes e o predador Chrysoperla externa (Hagen, 1861) (Neuroptera:Chrysopidae). Piracicaba, ESALQ/USP. 149p. (Dissertação de Mestrado).

PETERS, T.M. e P. BARBOSA, 1977. Influence population density on size, fecunaity, and development rote of insects in culture. Annual Review of Entomology. Palo Alto, 22: $431-450$.

PRESCOTT III, J.A. A R.M. BARANOWSKI, 1971. Effects of temperature on the immature stages of Anastrepha suspensa. (Diptera:Thephritidae). The Florida Entomologist. Gai$\therefore$ nesville, 54 (4):297-303. 
PROKOPY, R.J. E E.F. BOLLER, 1971. Response of European Cherry fruit flies to colored retangles. Journal of Economic Entomology. College Park, 64:1444-1447.

PROKOPY, R.J., 1972. Response of Apple Maggot flies to retangles of different colors and shades. Environmental Entomology. College Park, 1:720-726.

POLLONI, Y.J., 1981. Aspectos do comportamento reprodutivo de algumas espécies de mosca-de-fruta do gênero Anastré. pha Schiner, 1868 (Diptera:Tephritidae) em laboratörio . Ribeirão Preto, Faculdade de Medicina/USP. 98p. (Disser tação de Mestradol.

PUZŻI, D. e A. ORLANDO, 1965. Estudos sobre a ecologia das moscas-das-frutas (Tephritidae) no Estado de São Paulo, visando o controle racional da praga. Arquivo do Instituto Biológico. São Paulo, 32:9-22.

RHODE, R.H., 1957. A diet of Mexican fruit flies Anastrepha Zudens. Journal of Economic Entomology. ' College Park , $\underline{50}: 215$.

ROSSILO, M.A. E M.M. PORTILLO, 1971. Factóres que ditienen el incremento de la densidad de poblacion de las especies "Anastrepha fraterculus" (Wiedmann) y Ceratitis capitata (Wiedmann) (Dipt. Acalypt.). Revista Peruana de Entomo-

logia. Lima, 14 (2):323-333. 
SALGADO, L.O. e O. NAKANO, 1975. Inifluência de substâncias atrativas, cores e formas de armadilhas na captura da mosca-das-frutas Ceratitis capitata (Wiedemann, 1824) Dip tera:Tephritidae. In: CONGRESSO BRASILEIRO DE FRUTICULTU - RA, III, Rio de Janeiro, Sociedade Brasileira de Fruticul tura. v. 2, p.613-623.

SALGADO, L.O., 1979. Efeito biológico do oxicloreto de cobre sobre Ceratitis capitata (Wiedmann, 1824) (Diptera Te phritidae) em dieta artificial. Piracićaba, ESALQ/USP . 116p. (Tese de Doutoramento).

SEGUY, E., 1936. Code Universel des Couleurs. Paris, Libraire pour les Sciences Naturalles, n.p.

SGRILLO, R.B., 1982. A distribuição de WeibulI como modelo de sobrevivência de insetos. Ecossistema. Espírito San to do Pinhal, $\underline{7}: 9-13$.

SHOUKRY, A. e M. HAFEZ, 1979. Studies on the Biology of the Mediterranean fruit fly Ceratitis capitata. Entomologia Experimentalis et Applicata. Amsterdan, 26:33-39. 
SILVA, A.G.'d'A. de; C.R. GONÇALVES; D.M. GALVAO; A.J.L. GON ÇALVES; J. GOMES; M.N. SILVA E L. SIMONI, 1968. Quarto catálogo de insetos que vivem nas plantas do Brasil, seus hospedeiros e predadores. Rio de Janeiro, Ministério da Agricultura, v.1, pte.2, p.578-579.

SILVEIRA NETO, S.; O.NAKANO; D.BARBIN e N.A. VILLA NOVA,1976. Manual de ecologia dos insetos. São Paulo, Ceres, 419p.

SIMON, FO.J.E., 1968. Mass rearing of Anastrepha fratercuZus Wied. In: Present stage of research into the erradication of the Mediterranean and South American fruit flies and the cotton steiner in Peru by the sterile-male technique. (Proceding Symposio Vienna, 1967). Vienna., IAEA, P.116-119.

SIMÕES, M.H. e M.A. PALUDETTI, 1977. Duração do desenvölvi mento das formas jovens de Anastrepha obliqua (Diptera: Tephritidae) em laboratório. Ciência e Cultura: são Pau $10,29(7): 805 . \quad$ (Suplemento).

SIMÕES, M.H.; Y.J. POLLONI e M.A. PALUDETTI, 1978. Biologja de algumas espécies de Anastrepha (Diptera:Tephritidae)em

- laboratório. In: Resumos... III Congresso Latinoamerica no de Entomologia e V Congresso Brasileiro de Entomologia, Itabuna, Sociedade Entomológica do Brasil, n.p. 
SMITH, D.C. e R.J. PROKOPY, 1980. Mating behaviour of Rhagoletis pomonella (Diptera:Tephritidae). Site of early season encounters. Canadian Entomologist. Otawa, 112: 489-495.

SOUZA, H.M.L. de; O.H. de O. PAVAN e I.D. SILVA, 1984.

Oviposition and alightment behavior of Ceratitis capitata (Diptera, Tephritidae) on colored spheres. Revista Brasi. leira de Entomologia. São Paulo, 28(1):11-14.

SPISHAKOFF, L.M., 1966. Laboratory rearing of Anastrepha serpentina. Journal of Economic Entomology. College Park, 59 (4) : 1010-1011.

STEINER, L.F. e S. MITCHELL, 1966. Tephritid fruit flies . In: Smith, C.N. ed. Insect Colonization and Mass Production. New York: Academic Press. 618p.

SUGIMOTO, A., 1978. Mass rearing of larvae of the Melon fly, Dacus cucurbitae Coquillett (Diptera:Tephritidae) . Japan Journal Applied Entomology and Zoology. Okinawa , 22:219-227. 
SUPLICY FILHO, N.; A.S. SAMPAIO e I. MYAZAKI, 1978. Flutuação pópulacional das "moscas-das-frutas" (Anastrepha spp. e Ceratitis capitata Wied., 1824), em citros, na fazenda Guanabara, Barretos, SP. O Biológico. São Paulo; $\underline{44}$ (11) :279-284.

TANAKA, N., 1965. Artificial egging receptacles for three species of Tephritid flies. Journal of Economic Entomology. College Park, 58:177-178.

TORNISIELO, V.L., 1985. Influência do fotoperíodo e radiação gama na etologia da oviposição de Ceratitis capitata (Wiedemann, 1824) (Diptera-Tephritidae). Piracicaba , ESALQ/USP. 48p. (Dissertação de Mestrado).

TZANAKAKIS, M.E.; J.A. TSITSIPIS E L.F. STEINER, 1967. Egg production of Olive fly fed solids or liquids containing protein hydrolysate. Journal of Economic Entomology . College Park, 60(2):352-354.

VAN DER MOLEN, Y.F. , 1982. Dispersão e tamanho de uma popu lação de Anastrepha fraterculus (Wiedemann) (Diptera: Tephritidae). São Paulo, Instituto de Biociências da USP, 97p. (Dissertação de Mestrado). 
VARGAS, R.I., 1984. Alternative egg collection system for mass production of Mediterranean fruit fly (Diptera : Tephritidae). Journal of Economic Entomology. College Park, $77(4): 1064-1069$.

WASBAUER, M.S., 1972. An annotated host catalog of the fruit flies of America North of México (Diptera:Tephritidae). California, Bureau of Entomology, Departament of Agriculture, 172p. (Ocassional Papers, 19).

ZUCOLOTO, F.S.; S. PUSCHEL A C.M. MESSAGE, 1979. Dieta artificial para larva de Anastrepha sp. In: Resumos 3la Reunião Anual da Sociedade Brasileira para o Progresso da Ciência, Campinas, p.495.

ZUCCHI, R.A., 1978. Taxonomia das espécies de Anastrięhha Schiner, 1868 (Diptera, Tephritidae) assinaladas no Brasil. Piracicaba, ESALQ/USP. 105p. (Tese de Doutorámento) . 